\title{
Factors Affecting Site Response to Multi-directional Earthquake Loading
}

\author{
J. Yang ${ }^{1}$ and X.R. Yan ${ }^{1}$
}

\begin{abstract}
This paper presents an investigation into various factors that may affect the ground response to multi-directional earthquake loading, focusing mainly on the behavior of vertical ground motion and its relation with the horizontal counterpart. The factors investigated herein include the intensity of input motion and the associated soil nonlinearity, the location of input motion (rock outcrop versus bedrock), the variation of water table, and the damping property of soil. Influence of these factors is studied on the characteristics of site amplification in both vertical and horizontal directions, the response spectra of vertical and horizontal ground surface motions, the spectral ratio between the two components $(\mathrm{V} / \mathrm{H})$ at the ground surface, and the distributions of stresses and strains in the ground. One of the main results is that varying water table can bring about a significant impact on vertical motion and the the relationship between vertical and horizontal motions. The surface response spectral ratio $(\mathrm{V} / \mathrm{H})$ can largely exceed the rule-of-thumb value $2 / 3$ at low periods with lowering the water table, but does not appear to be substantially affected at long periods.

Key words: earthquakes; ground motion; site response; soil damping; soil nonlinearity
\end{abstract}

\footnotetext{
${ }^{1}$ Department of Civil Engineering, The University of Hong Kong, Hong Kong (E-mail: junyang@hku.hk)
} 


\section{INTRODUCTION}

26 Evaluation of site response to earthquakes plays an important role in seismic design

27 of engineering structures. Most of site response analyses have concentrated on

28 horizontal ground motion, in which site response is regarded as the consequence of

29 the vertical propagation of shear waves in a horizontally layered system. Although it

30 has long been recognized that the ground is simultaneously subjected to shaking in

31 both horizontal and vertical directions during a real earthquake, vertical ground

32 motion, as compared with its horizontal counterpart, has received much less

33 attention. As a result, knowledge with regard to the characteristics of vertical ground

34 motion and, particularly, with regard to relating vertical and horizontal ground

35 motions is rather limited. The common procedure for generating vertical design

36 spectra, as documented in many seismic provisions and codes (e.g., UBC, 1997), is to

37 simply multiply a factor (typically a value of $2 / 3$ ) to the horizontal design spectra

38 (Fig. 1). In other words, it is assumed that the response spectral ratio between vertical

39 and horizontal motions is a constant less than 1 over the entire period of interest and

40 for all site conditions.

41 However, several studies on ground motion records obtained in recent

42 earthquakes have shown that the constant $(\mathrm{V} / \mathrm{H})$ ratio is not a good descriptor (e.g.,

43 Yang and Sato, 2000; Elgamal and He, 2004; Yang and Lee, 2007). The response

44 spectral ratio $(\mathrm{V} / \mathrm{H})$ depends on a number of factors (e.g., site-to-source distance and

45 source mechanism), and can be significantly greater than $2 / 3$ at short periods in

46 moderate and large earthquakes. In the most recent Wenchuan, China earthquake of 
47 May 12, 2008, vertical ground acceleration as large as $0.633 \mathrm{~g}$ ( $g$ is the gravity) was

48 recorded in the epicenter zone.

49 From a geotechnical engineering perspective, it is of particular interest to

50 identify the influence of such factors as the intensity of earthquake motion, the

51 location of input motion (or control motion), the depth of water table, and the

52 damping property of soil on the behavior of vertical motion as well as its relation

53 with the horizontal motion. This is precisely the purpose of the present study. In an

54 earlier study by Yang and Yan (2009), a simple procedure was proposed for analysis

55 of the ground response under both vertical and horizontal earthquake loading;

56 validation of the analytical procedure against the downhole array records at the

57 Turkey Flat test site in California showed reasonably good agreement between

58 predictions and measurements. By using this newly developed procedure, a series of

59 analyses have been carried out for a hypothesized site with the aim to explore several

60 potential influencing factors. The main results derived from these analyses are

61 presented in this paper.

\section{HYPOTHESIZED SITE AND INPUT MOTION}

64 The hypothetical soil site is shown in Fig. 2. The soil profile is $30 \mathrm{~m}$ deep comprising a

65 surface sandy clay layer of $10 \mathrm{~m}$ and an underlying sand layer of $20 \mathrm{~m}$. The water

66 table is located at the depth of $5 \mathrm{~m}$ below the ground level. The mass density of the

67 clay is assumed to be $1800 \mathrm{~kg} / \mathrm{m}^{3}$ and the density of the sand is $2000 \mathrm{~kg} / \mathrm{m}^{3}$. The shear

68 wave velocity, $V_{\mathrm{s}}$, varies from $170 \mathrm{~m} / \mathrm{s}$ in the clay layer to $350 \mathrm{~m} / \mathrm{s}$ in the sand layer. 
69 Using the UBC site classification system, the site can be categorized to be a stiff-soil

70 site. On the other hand, the compressional wave velocity, $V_{\mathrm{p}}$, is assumed to vary from

$71360 \mathrm{~m} / \mathrm{s}$ in the clay above the water level, to $1561 \mathrm{~m} / \mathrm{s}$ in the clay below the water level,

72 and to $1788 \mathrm{~m} / \mathrm{s}$ in the sand. The location of bedrock is assumed to be at the depth of

$7330 \mathrm{~m}$, with the shear wave velocity of $470 \mathrm{~m} / \mathrm{s}$ and the compressional wave velocity of

$742007 \mathrm{~m} / \mathrm{s}$.

75 The nonlinear behavior of the sandy clay in terms of the shear modulus

76 reduction curve and the damping ratio curve is described using the proposal by Sun

77 et al. (1988), while the nonlinear behavior of the sand is assumed to follow the curves

78 developed by Seed and Idriss (1970). The input motions used in this study are shown

79 in Fig. 3 in terms of acceleration time histories and response spectra at $5 \%$ damping.

80 They are the north-south and up-down components of the acceleration records

81 obtained at the Mount Wilson station during the 1987 Whittier Narrows earthquake

82 in California. The peak horizontal acceleration appearing at $2.84 \mathrm{~s}$ is $1.482 \mathrm{~m} / \mathrm{s}^{2}$, and

83 the peak vertical acceleration, $0.756 \mathrm{~m} / \mathrm{s}^{2}$, occurs at $3.08 \mathrm{~s}$. As can be seen in Fig. 3(b),

84 the spectral accelerations in both directions take the maxima at periods of 85 approximately $0.16 \mathrm{~s}$.

\section{INFLUENCE OF INPUT MOTION INTENSITY}

88 Among various measures of earthquake ground motion, peak acceleration has been

89 widely used in engineering practice to characterize the intensity of seismic loading.

90 To investigate its effect, the original horizontal and vertical acceleration records given 
91 in Fig. 3 are scaled simultaneously by multiplying factors of 0.5 and 2, respectively, to

92 produce two more sets of acceleration records having different intensity levels. The

93 three sets of records are referred to as Level 1, 2 and 3 hereafter. Analyses have been

94 performed by subjecting the hypothesized soil profile to these three sets of

95 accelerations, which were all specified at the rock outcrop (see Fig. 2).

96 Figure 4 shows the influence of motion intensity on the transfer functions for

97 horizontal and vertical motions. It is clear that site frequencies in both components

98 decrease with increasing intensity level or increasing peak acceleration. For Level 1

99 earthquake motion (the weakest case), the fundamental frequency is at $2.5 \mathrm{~Hz}$ for the

100 horizontal component and $12.5 \mathrm{~Hz}$ for the vertical component. By comparison, they

101 are reduced to be 2.2 and $11 \mathrm{~Hz}$ in the case of Level 3 earthquake motion. In the

102 meantime, peak values of the spectral ratios in both components are reduced

103 substantially when the intensity of input motion increases. For example, the vertical

104 amplification at the fundamental frequency drops from approximately 25 at Level 1

105 motion to about 13 at Level 3; the horizontal amplification at the fundamental

106 frequency varies from approximately 17 at Level 1 to less than 10 at Level 3 input 107 motion.

108 The above observations are mainly attributed, as will be shown later, to the

109 following two effects. First, higher peak acceleration causes a higher hysteretic

110 damping and therefore a larger reduction of site amplification. Second, higher peak

111 acceleration results in larger strains and reduced moduli and thus lower frequency 112 response. 
114 which is defined as the ratio between the peak acceleration at the ground surface and

115 the peak acceleration at the base of soil deposit (e.g., Idriss, 1990) Following this

116 practice, the amplification factors for both horizontal and vertical motions are

117 calculated for the three cases of intensity levels and summarized in Table 1. It is noted

118 that the amplification factor for horizontal motion decreases with increasing intensity

119 level. The amplification factor for vertical motion, however, is found to be an

120 increasing function of the intensity level. This implies that the so-defined

121 amplification factor, as compared with the transfer function given in Fig. 4, is not an

122 appropriate indicator for soil nonlinearity involved with vertical motion.

123 As far as the ratio between peak vertical and horizontal accelerations $(\mathrm{V} / \mathrm{H})$ is

124 concerned, it is interesting to note that the ratio increases with increasing intensity at

125 the ground surface but decreases with increasing intensity at the base of the soil

126 deposit. Consequently, the surface-to-base $(\mathrm{V} / \mathrm{H})$ ratio is an increasing function of the

127 intensity of input motion.

128 The influence of the intensity of input motion on surface response spectra is

129 shown in Fig. 5 for both horizontal and vertical motions. Again, the influence is

130 observed to be significant on both components. In the case of Level 1 input motion,

131 the peak spectral acceleration in the horizontal direction is approximately $1 / 3$ of that

132 under Level 3 input motion. Similarly, the peak spectral acceleration in vertical

133 direction at Level 3 is about 5 times the peak value at Level 1 input motion. It is worth

134 noting from Fig. 6 that, while the intensity of input motion has a profound influence 
135 on both individual components, its impact on the response spectral ratio between the

136 vertical and horizontal motions $(\mathrm{V} / \mathrm{H})$ appears to be less significant. With increasing

137 the motion intensity, a slight increase in the $(\mathrm{V} / \mathrm{H})$ spectral ratio occurs for periods

138 lower than $0.2 \mathrm{~s}$; for longer periods the influence becomes negligible and the $(\mathrm{V} / \mathrm{H})$

139 ratio is generally less than $2 / 3$. In the period range of $0.05-0.2 \mathrm{~s}$, the $(\mathrm{V} / \mathrm{H})$ ratio

140 substantially exceeds $2 / 3$ regardless of the intensity of input motion.

141 Shown in Fig. 7 are the variations with depth of peak accelerations in

142 horizontal and vertical directions for the three intensity levels. The influence of the

143 motion intensity on the profiles of peak stresses and peak strains is presented in Fig. 8.

144 Generally, higher intensity level causes larger response in both components. It is to be

145 noted that there is a dramatic variation in peak horizontal acceleration occurring at a

146 depth of 5 to $10 \mathrm{~m}$, while a high gradient of peak vertical acceleration appears at a

147 depth of about $5 \mathrm{~m}$. Significant variations in shear and normal strains are observed in

148 similar zones. Recalling the soil profiles given in Fig. 2, the observed variations are

149 considered reasonable.

$150 \quad$ Figure 9 presents the profiles of the degraded shear and constrained moduli

151 and the shear-strain compatible damping ratio $\left(\zeta_{h}\right)$ under different intensity levels of

152 input motion. It can be seen that the higher the input motion intensity, the smaller the

153 moduli and the larger the damping ratio. With respect to the shear modulus, the

154 influence of intensity tends to be appreciable in the sand layer below the depth of 10

$155 \mathrm{~m}$. The influence on the constraint modulus, however, becomes notable for soils

156 below the depth of $5 \mathrm{~m}$. This is consistent with the previous observation on the 
variation of normal strain, and is thought to be associated with the variation of the

158 compressional wave velocity and Poisson's ratio with depth.

\section{INFLUENCE OF LOCATION OF INPUT MOTION}

161 In site response analysis there are generally two options to input earthquake motion:

162 one is to specify the motion at a rock outcrop, as done in the above case analyses, and

163 the other is at the bedrock or soil-rock interface (Fig. 2). In the former case the

164 incident waves are equal in amplitude with the reflected waves at the rock outcrop,

165 as required by the free-stress condition. In the theoretical procedure used herein, this

166 case is handled by introducing a radiation dashpot at the soil-rock interface, with the

167 damping coefficients determined from the properties of the bedrock. For the later

168 case, the response of the site can be established directly by solving the displacement-

169 force equation as described by Yang and Yan (2009). Since there has been confusion

170 with the bedrock and outcrop inputs, an effort is made here to clarify this issue by

171 examining the difference in ground response for two cases: in one case the

172 earthquake motion is input at the rock outcrop and in the other case the same motion

173 is input at the bedrock.

174 Using the acceleration records given in Fig. 3 as the bedrock and outcrop input

175 respectively, the response spectra of ground surface motions were calculated and are

176 compared in Fig. 10. In both plots the curves for the case of outcropping input are

177 denoted as "outcropping" while the curves generated from the case of bedrock input

178 are labeled as "bedrock". Shown in Fig. 11 are the profiles of peak accelerations in 
179 both directions for the two cases. The results for stresses and strains in the two cases 180 are presented in Fig. 12.

181 The overall observation on these figures is that, compared with the case of 182 outcropping input, the response of the site to the same earthquake motion but input 183 at the bedrock is stronger in both vertical and horizontal directions. Accordingly, in 184 the case of bedrock input more significant modulus reduction and higher damping 185 are observed (Fig. 13). These observations are reasonable because in the outcropping 186 case, perfect reflection occurs due to the free stress conditions (i.e. reflected waves are 187 equal to incident waves), whereas in the bedrock case part of the incident waves are 188 transmitted into the soils resulting in the reflected waves of being less than the 189 incident waves. More detailed discussion on the relation between bedrock motion 190 and outcropping motion can be referred to Yang and Yan (2009).

191 Moreover, the difference in the modulus reduction and damping ratio will 192 bring about changes in site frequencies in both horizontal and vertical components.

193 For example, the fundamental frequency of the vertical motion in the case of bedrock 194 input is about $94 \%$ of that in the case of outcropping input. It should be noted that the 195 change of input motion position will not cause difference in the transfer function for 196 either component if the nonlinear behavior of the soil is not taken into account. With respect to the response spectral ratio $(\mathrm{V} / \mathrm{H})$ at the ground level, Fig. 14 198 shows that the ratio is substantially increased at short periods (less than $0.2 \mathrm{~s}$ ) but 199 slightly decreased at periods longer than $0.2 \mathrm{~s}$ when the location of input motion 200 changes from rock outcrop to the base of the soil deposit. 
the two cases of input motion position. Note that the influence of input motion position is more significant for vertical motion than for horizontal motion; this is also accelerations at the ground surface, the results show that it increases from 0.5 for outcropping input to 0.98 for bedrock input.

\section{INFLUENCE OF WATER LEVEL}

209 The analysis of Yang and Sato (2000) on the downhole array records at a reclaimed

210 site in Kobe, Japan has indicated that the variation of water table plays an important 211 role in the amplification of vertical ground motion. To further investigate this effect,

212 three cases of water levels are examined in parallel in this section (Fig. 15): the first

213 case is for water level at the surface (i.e. $W L=0 \mathrm{~m}$ ), the second case is for water level at

$2145 \mathrm{~m}$ below the surface (i.e. the case discussed previously), and in the third case the

215 depth of water table is at $10 \mathrm{~m}$. Note that in the three cases the profiles of the shear 216 wave velocity $\left(V_{s}\right)$ are assumed to be identical but the profiles of the compressional 217 wave velocity $\left(V_{\mathrm{p}}\right)$ vary with the change of water table. In the case of $\mathrm{WL}=0 \mathrm{~m}, V_{\mathrm{p}}$ is 218 assumed to vary from $1561 \mathrm{~m} / \mathrm{s}$ in the clay layer to $1785 \mathrm{~m} / \mathrm{s}$ in the underlying sand, 219 whereas in the case of $\mathrm{WL}=10 \mathrm{~m}$, it is assumed to vary from $360 \mathrm{~m} / \mathrm{s}$ in the clay to $2201785 \mathrm{~m} / \mathrm{s}$ in the sand layer.

221 The above assumption for the variations of $V_{\mathrm{p}}$ and $V_{\mathrm{s}}$ is based on the results of 222 the studies by Yang and Sato (2000) and Yang et al. (2004), which indicate that the 
223 presence of ground water has a significant influence on the compressional wave

224 velocity but little influence on the shear wave velocity and that a dramatic change in

225 the compressional wave velocity may occur at the location of water table.

226 Figure 16 compares vertical ground surface motions computed for the three 227 water levels in terms of the acceleration time histories. Shown in Fig. 17 is the

228 influence of water level on the surface response spectra and the transfer function for 229 vertical motion. Clearly, the variation of water table brings about a profound effect on 230 the behavior of vertical motion. The transfer function will be shifted to the low 231 frequency end when the water table is lowered. For example, the fundamental 232 frequency is found to be at $13.4 \mathrm{~Hz}$ when the water table is at the ground surface, but 233 it drops to $7.4 \mathrm{~Hz}$ when the depth of water table becomes $10 \mathrm{~m}$. In the meantime, 234 lowering water table brings about a much stronger amplification of vertical motion, 235 as can be seen from Fig. 17(a). The peak spectral acceleration in the case of $\mathrm{WL}=10 \mathrm{~m}$ 236 is about 3 times that in the case of $\mathrm{WL}=0 \mathrm{~m}$.

237 With respect to the relation between vertical and horizontal motions, Fig. 18 238 shows that the variation of water table can also significantly affect the response 239 spectral ratio $(\mathrm{V} / \mathrm{H})$ at the ground surface. For water level at the surface, the $(\mathrm{V} / \mathrm{H})$ 240 spectral ratio is generally below the value of $2 / 3$ in the whole range of period. If the 241 water level is lowered to the depth of $10 \mathrm{~m}$, the ratio will increase sharply for periods 242 shorter than about $0.2 \mathrm{~s}$, with the peak value of as large as 2.3. On the other hand, the 243 influence of varying water table is found to be slight for the spectral ratio $(\mathrm{V} / \mathrm{H})$ at 244 periods longer than $0.6 \mathrm{~s}$. 
246 and vertical velocity under different water levels. High gradients are found to occur

247 at the depth that is close to the water table. Taking the case of $W L=10 \mathrm{~m}$ as an

248 example, peak vertical acceleration is increased only by $26 \%$ when seismic waves

249 travel from the base to the depth of $10 \mathrm{~m}$; but it is increased by $200 \%$ when the waves

250 further propagate from the depth of $10 \mathrm{~m}$ to the ground surface. This result highlights

251 the importance of varying water table in vertical site amplification, and is in

252 agreement with the observation on the downhole array records in the Kobe

253 earthquake (Yang and Sato, 2000).

254 For ease of reference, Table 3 summarizes the peak values of vertical surface 255 accelerations under different water levels. It is worth noting that the peak vertical 256 acceleration at $\mathrm{WL}=10 \mathrm{~m}$ is about 2.6 times that at $\mathrm{WL}=0 \mathrm{~m}$. The peak acceleration 257 ratio $(\mathrm{V} / \mathrm{H})$ accordingly increases from 0.37 in the case of $\mathrm{WL}=0 \mathrm{~m}$ to 0.96 at $\mathrm{WL}=10 \mathrm{~m}$.

259 INFLUENCE OF DAMPING RATIO

260 The damping property of soils associated with shear wave propagation has been 261 studied extensively (e.g., Sun et al., 1988; Vucetic and Dobry, 1991; Ishihara, 1996).

262 Current knowledge of soil damping with respect to the propagation of compressional 263 waves is however very limited, although several attempts have been made to discuss 264 the combined loading effect (e.g., Zhang and Aggour, 2004). In the previous case 265 studies, the damping ratio for vertical motion $\left(\zeta_{v}\right)$ was assumed to be identical with 266 the damping ratio for horizontal motion $\left(\zeta_{h}\right)$, which was derived from the horizontal 
267 site response analysis through iterations. It is necessary to examine the potential

268 effect of damping ratio, $\zeta_{v}$, on the vertical site response. For this purpose, two more

269 cases of vertical damping, $\zeta_{v}=0.5 \zeta_{h}$ and $\zeta_{v}=2 \zeta_{h}$, are assumed for the reference soil

270 profile given in Fig. 2.

271 The surface response spectra of vertical motion under three damping ratios

272 are presented in Fig. 20(a). The transfer functions for vertical motion under the three

273 damping ratios are presented in Fig. 20(b). As expected, an increase in damping ratio

$274\left(\zeta_{v}\right)$ results in a greater reduction in vertical amplification. In the case of low

275 damping ratio, i.e. $\zeta_{v}=0.5 \zeta_{h}$, the vertical amplification at the fundamental frequency

276 is as large as 37; but it is reduced to be less than 10 when $\zeta_{v}=2 \zeta_{h}$. On the other hand,

277 the influence of vertical damping ratio on the surface response spectra appears to be

278 minor for the entire range of periods. Accordingly, the surface response spectral ratio

$279(\mathrm{~V} / \mathrm{H})$ is not significantly affected by the variation of vertical damping (Fig. 21).

280 The influence of damping ratio on peak vertical acceleration and velocity at

281 ground surface is summarized in Table 4. It is noted that when the damping ratio is

282 decreased from $2 \zeta_{h}$ to $0.5 \zeta_{h}$, the peak acceleration ratio $(\mathrm{V} / \mathrm{H})$ is increased by $10 \%$,

283 from 0.48 to 0.54 .

285 IMPLICATIONS FOR PRACTICE

286 The results presented in the preceding sections indicate that the current practice to

287 produce vertical response spectra for seismic design is not adequate as the response

288 spectral ratio $(\mathrm{V} / \mathrm{H})$ is influenced by a number of geotechnical factors, in addition to 
source mechanism and site-to-source distance. In particular, the behavior of vertical

290 motion can be significantly affected by the variation of water table or the associated

291 variation in compressional wave velocity, which may occur in certain circumstances

292 such as change of seasons. It is thus necessary to examine the water table conditions

293 in interpreting vertical earthquake motion recordings. A good example can be

294 referred to the study of Yang and Sato (2000).

295 The results presented here also have useful implications for the applications of 296 the site-evaluation technique known as $(\mathrm{H} / \mathrm{V})$, which is based on the interpretation of 297 recordings of microtremors or weak ground motions in both horizontal and vertical 298 components and has drawn an increasing interest in practice (e.g., Mucciarelli et al., 299 2003),

300 Since there is possibility that vertical motion at the ground surface can become 301 comparable to or even larger than its horizontal counterpart in magnitude, it is 302 necessary to take into account a wider range of magnitudes of vertical motion in 303 seismic analysis and design of engineering structures. Several recent studies have 304 shown that the effect of vertical motion should not be simply disregarded (Ling and 305 Leshchinsky, 1998; Mylonakis and Gazetas, 2002; Yang, 2007).

306 Owing to the simplifications introduced in the present modeling procedure, 307 the effects on ground motions due to very strong nonlinear soil response, in 308 particular that associated with soil liquefaction (e.g., Yang et al., 2000), may not be 309 well accounted for. In these situations more sophisticated procedures such as fully310 coupled, elasto-plastic, 2D or 3D finite element programs can be sought to investigate 
311 the ground motion characteristics. However, it is to be recognized that these analyses

312 usually involve with great difficulty and uncertainty in determination of the

313 parameters of constitutive models for soils, rendering them unsuitable for routine

314 engineering practice.

316 CONCLUSIONS

317 An attempt has been made in this study, by using a simple analytical procedure 318 developed by Yang and Yan (2009), to investigate potential factors that may influence

319 ground response to vertical and horizontal earthquake loading. Particular attention

320 has been paid to the behavior of vertical ground motion and its relation with the 321 horizontal counterpart, on which current understanding is very limited. The main 322 results of the present study can be summarized as follows.

323 (a) Site frequencies for both vertical and horizontal motions decrease with 324 increasing the intensity of input motion, accompanied by a significant reduction 325 of site amplification at these frequencies. This is due primarily to high hysteretic 326 damping and reduced moduli associated with strong earthquake motion.

327 (b) While the intensity of input motion has a profound influence on the 328 characteristics of individual components of ground motions, its impact is 329 however less significant on the response spectral ratio between the vertical and 330 horizontal motions $(\mathrm{V} / \mathrm{H})$ at the surface. 
331 (c) The amplification factor, simply defined as the ratio between peak accelerations

332 at the surface and at the base of soil deposit, is not an appropriate indicator for

333 soil nonlinearity involved with vertical ground motion.

334 (d) Compared with the case of rock outcropping input, the response of the site to

335 the same earthquake motion specified at the bedrock is stronger in both vertical

336 and horizontal directions. Vertical ground response appears to be affected more

337 significantly by the location of input motion than the horizontal one.

338 (e) The variation of water table can bring about a significant impact on vertical

339 ground response. When the water table is lowered, site frequencies for vertical

340 motion will be shifted to the low frequency end and the surface response spectra

$341 \quad$ will exhibit higher peak values.

342 (f) The surface response spectral ratio $(\mathrm{V} / \mathrm{H})$ increases substantially at low periods

343 with lowering the water table, but is not affected significantly at long periods

344 (greater than $0.6 \mathrm{~s}$ ). The peak value of the spectral ratio $(\mathrm{V} / \mathrm{H})$ tends to largely

345 exceed the rule-of-thumb value $2 / 3$ when the water table is lowered.

346 (g) The vertical amplification at site frequencies decreases with increasing the 347 damping ratio for vertical motion, but the influence of damping ratio appears to

348 be minor on the response spectra of vertical surface motion and on the response 349 spectral ratio $(\mathrm{V} / \mathrm{H})$ at the surface. 
352 The work described in this paper was supported by the Research Grants Council of 353 Hong Kong (Grant numbers: HKU7127/04E and HKU7191/05E). This support is 354 gratefully acknowledged.

\section{REFERENCES}

357 Elgamal, A. and He, L. 2004. Vertical earthquake ground motion record: An 358 overview. Journal of Earthquake Engineering 8, 663-697.

359 Idriss, I.M. 1990. Response of soft soil sites during earthquakes. Proceedings of the

360 Symposium to Honor Professor H.B. Seed, Berkeley, California, 273-289.

361 Ishihara, K. 1996. Soil behaviour in earthquake geotechnics. Oxford: Clarendon Press. 362 Ling, H. I. and Leshchinsky, D. 1998. Effects of vertical acceleration on seismic design 363 of geosynthetic-reinforced soil structures. Géotechnique 48(3), 347-373.

364 Mucciarelli, M., Gallipoli, M.R. and Arcieri, M. 2003. The stability of the horizontal-to365 vertical spectral ratio of triggered noise and earthquake recordings. Bulletin of 366 the Seismological Society of America 93(3), 1407-1412.

367 Mylonakis, G. and Gazetas, G. 2002. Kinematic pile response to vertical P-wave 368 seismic excitation. Journal of Geotechnical and Geoenvironmental Engineering, $369 \quad$ ASCE $128(10), 860-865$.

370 Seed, H. B. and Idriss, I. M. 1970. Soil moduli and damping factors for dynamic 371 response analyses. Report EERC 70-10, Earthquake Engineering Research Center, $372 \quad$ University of California, Berkeley. 
373 Sun, J. I., Golesorkhi, R. and Seed, H. B. 1988. Dynamic moduli and damping ratios

374 for cohesive soils. Report UCB/EERC 88/15, Earthquake Engineering Research

375 Center, University of California, Berkeley.

376 UBC 1997. Uniform Building Code. International Conference of Building Officials, 377 Whittier, California.

378 Vucetic, M. and Dobry, R. 1991. Effect of soil plasticity on cyclic response. Journal of 379 Geotechnical Engineering, ASCE 117(1), 89-107.

380 Yang, J. 2008. On seismic landslide hazard assessment. Géotechnique 57(8), 707-713.

381 Yang, J. and Lee, C.M. 2007. Characteristics of vertical and horizontal ground motions 382 recorded during the Niigata-ken Chuetsu, Japan earthquake of 23 October 2004. $383 \quad$ Engineering Geology 94(1-2), 50-64.

384 Yang, J. and Sato, T. 2000. Interpretation of seismic vertical amplification observed at 385 an array site. Bulletin of the Seismological Society of America 90(2), 275-285.

386 Yang, J., Sato, T. and Li, X.S. 2000. Nonlinear site effects on strong ground motion at a 387 reclaimed island. Canadian Geotechnical Journal 37, 26-39.

388 Yang, J., Savidis, S. and Roemer, M. 2004. Evaluating liquefaction strength of partially 389 saturated sand. Journal of Geotechnical and Geoenvironmental Engineering, $390 \quad$ ASCE 130(9), 975-979.

391 Yang, J. and Yan, X.R. 2009. Site response to multi-directional earthquake loading: A 392 practical procedure. Soil Dynamics and Earthquake Engineering 29, 710-721. 
393 Zhang, X. J. and Aggour, M. S. 2004. Effects of coupled vibrations on the dynamic 394 properties of sands. Proceedings of the 13th World Conference on Earthquake $395 \quad$ Engineering, Vancouver, Canada.

396 
398 Figure 1. Schematic illustration of the common procedure for generating vertical design

spectra from the horizontal design spectra

Figure 2. A hypothesized site for analysis

Figure 3. Input motions used: (a) time histories; (b) response spectra

Figure 4. Transfer functions (surface-to-base) under various levels of motion intensity: (a) horizontal component; (b) vertical component

Figure 5. Response spectra of ground surface motions under various levels of motion intensity: (a) horizontal component; (b) vertical component

Figure 6. Influence of the intensity of input motion on the response spectral ratio between vertical and horizontal surface motions $(\mathrm{V} / \mathrm{H})$

Figure 7. Influence of the intensity of input motion on distributions of peak accelerations with depth: (a) horizontal component; (b) vertical component

Figure 8. Influence of the intensity of input motion on distributions of stresses and strains with depth: (a) peak shear stress; (b) peak shear strain; (c) peak normal stress; (d) peak normal strain

Figure 9. Influence of the intensity of input motion on distributions of degraded moduli and damping with depth: (a) shear modulus; (b) constrained modulus; (c) damping ratio

Figure 10. Influence of input motion position on the response spectra of ground surface motions: (a) horizontal component; (b) vertical component

Figure 11. Influence of input motion position on distributions of peak accelerations with depth: (a) horizontal component; (b) vertical component

Figure 12. Influence of input motion position on distributions of stresses and strains with depth: (a) peak shear stress; (b) peak shear strain; (c) peak normal stress; (d) peak normal strain

Figure 13. Influence of input motion position on distributions of (a) shear modulus reduction and (b) damping ratio

Figure 14. Influence of input motion position on the response spectral ratio between vertical and horizontal surface motions $(\mathrm{V} / \mathrm{H})$

Figure 15. Three cases of water levels under investigation: (a) $W L=0 \mathrm{~m}$; (b) $W L=5 \mathrm{~m}$; (c) $\mathrm{WL}=10 \mathrm{~m}$ 
443 Figure 16. Vertical ground surface accelerations under various water levels: (a) $W L=0 \mathrm{~m}$;

444 (b) $W L=5 \mathrm{~m}$; (c) $\mathrm{WL}=10 \mathrm{~m}$

445

446 Figure 17. Influence of water level on vertical ground motion: (a) surface response spectra;

447 (b) transfer function (surface-to-base)

448

449

Figure 18. Influence of water level on the response spectral ratio between vertical and

450 horizontal surface motions $(\mathrm{V} / \mathrm{H})$

451

452

Figure 19. Influence of water level on distributions of (a) peak vertical acceleration and (b)

453 peak vertical velocity

454

455

456

457

458 Figure 21. Influence of damping ratio on the response spectral ratio between vertical and 459 horizontal surface motions $(\mathrm{V} / \mathrm{H})$

460 


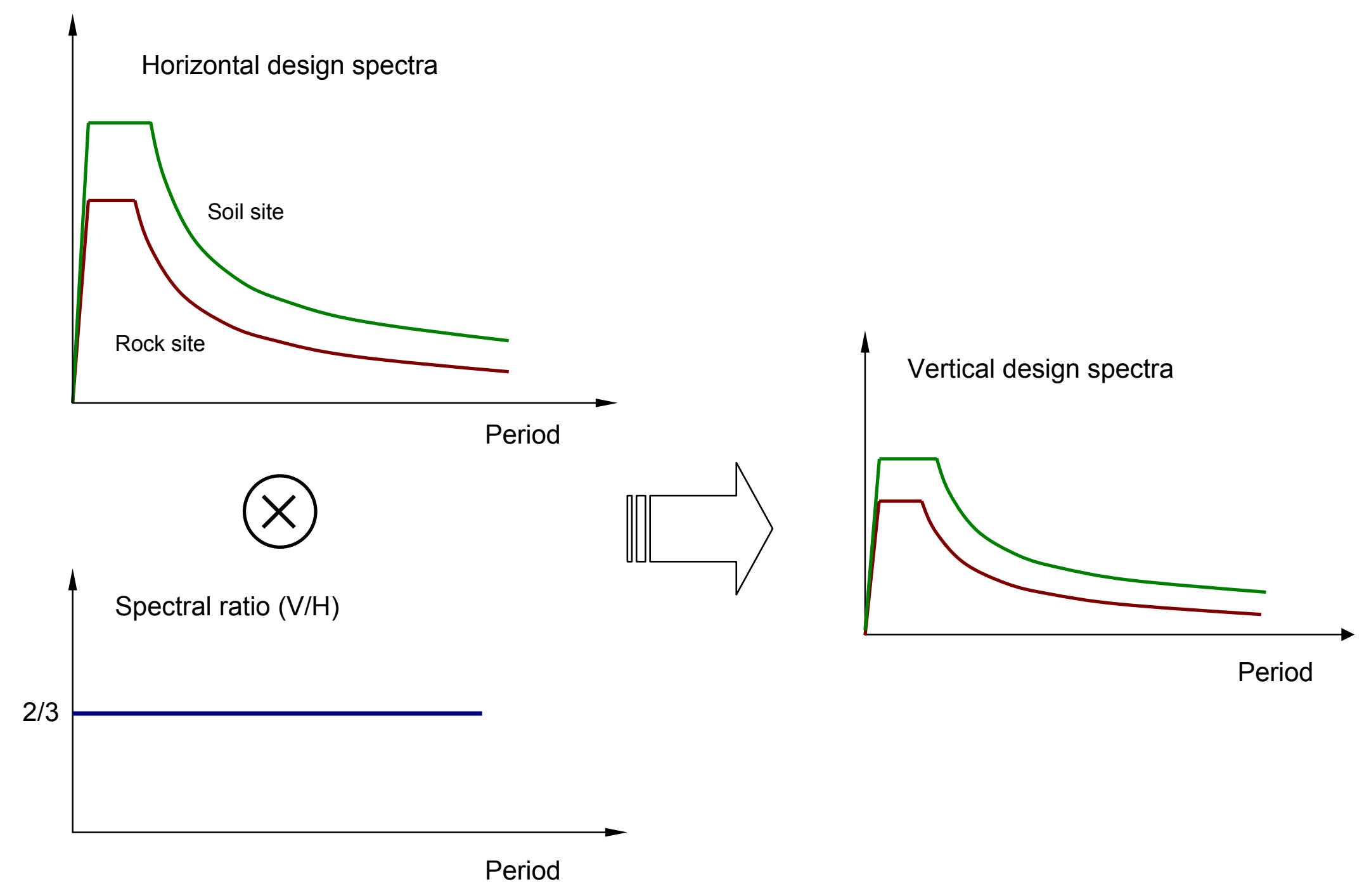

Figure 1. Schematic illustration of the common procedure for generating vertical design spectra from the horizontal design spectra 


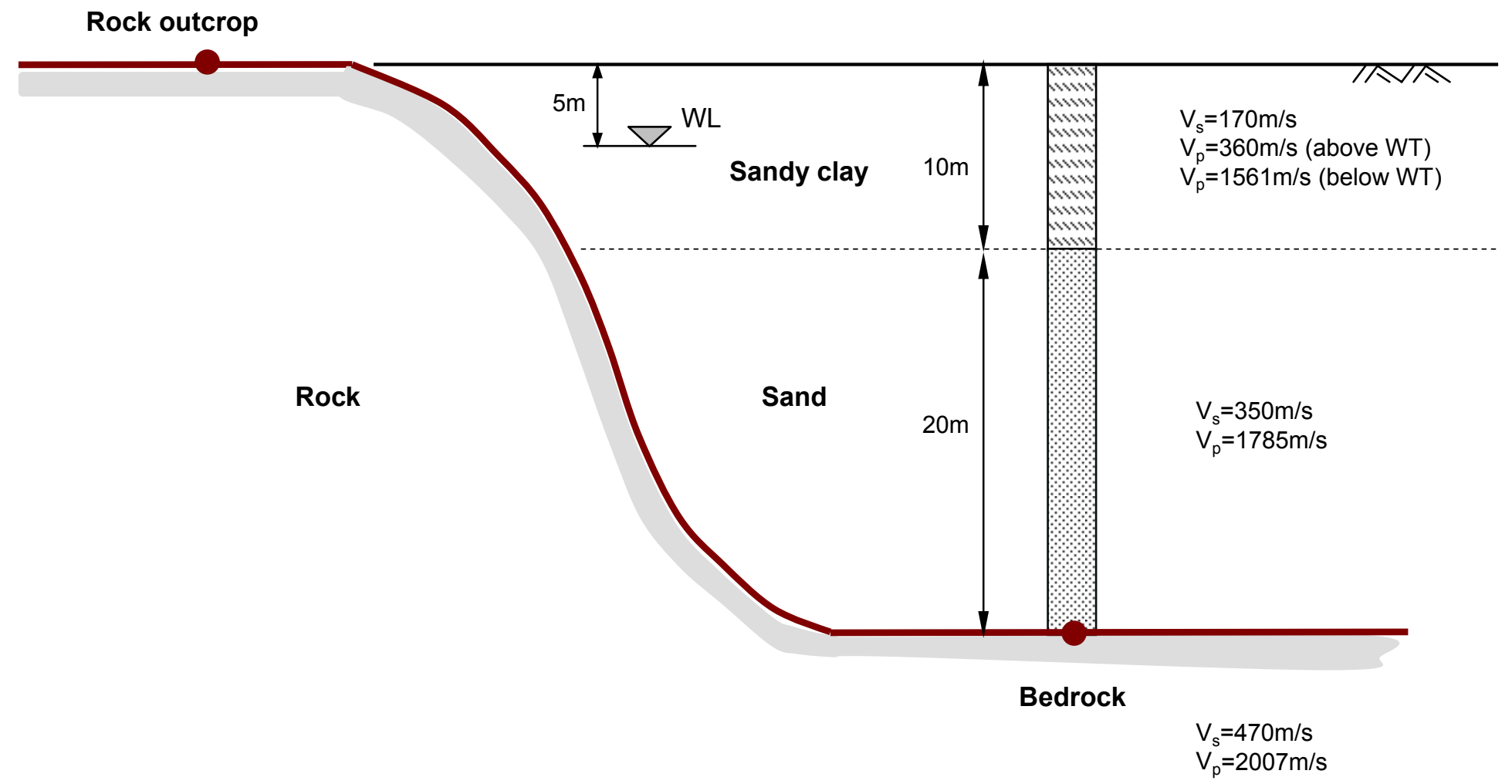

Figure 2. A hypothesized site for analysis 


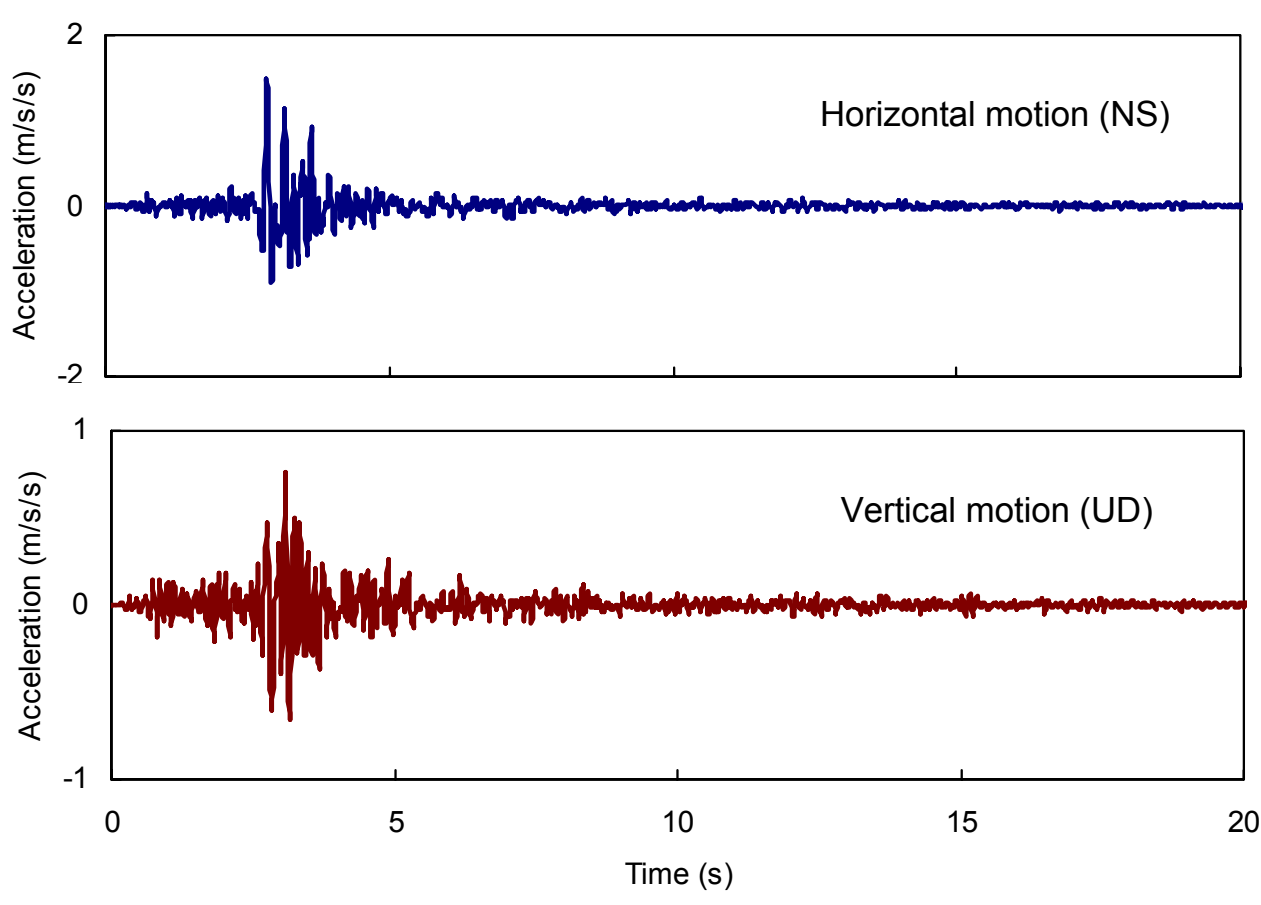

(a)

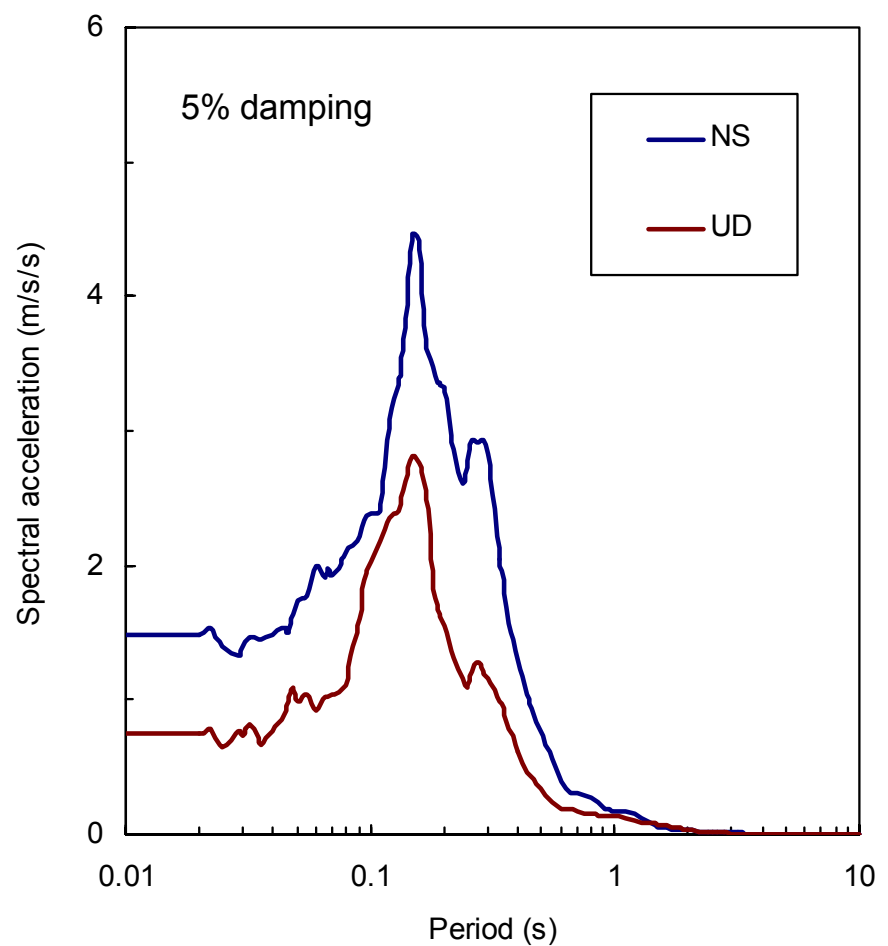

(b)

Figure 3. Input motions used: (a) time histories; (b) response spectra 


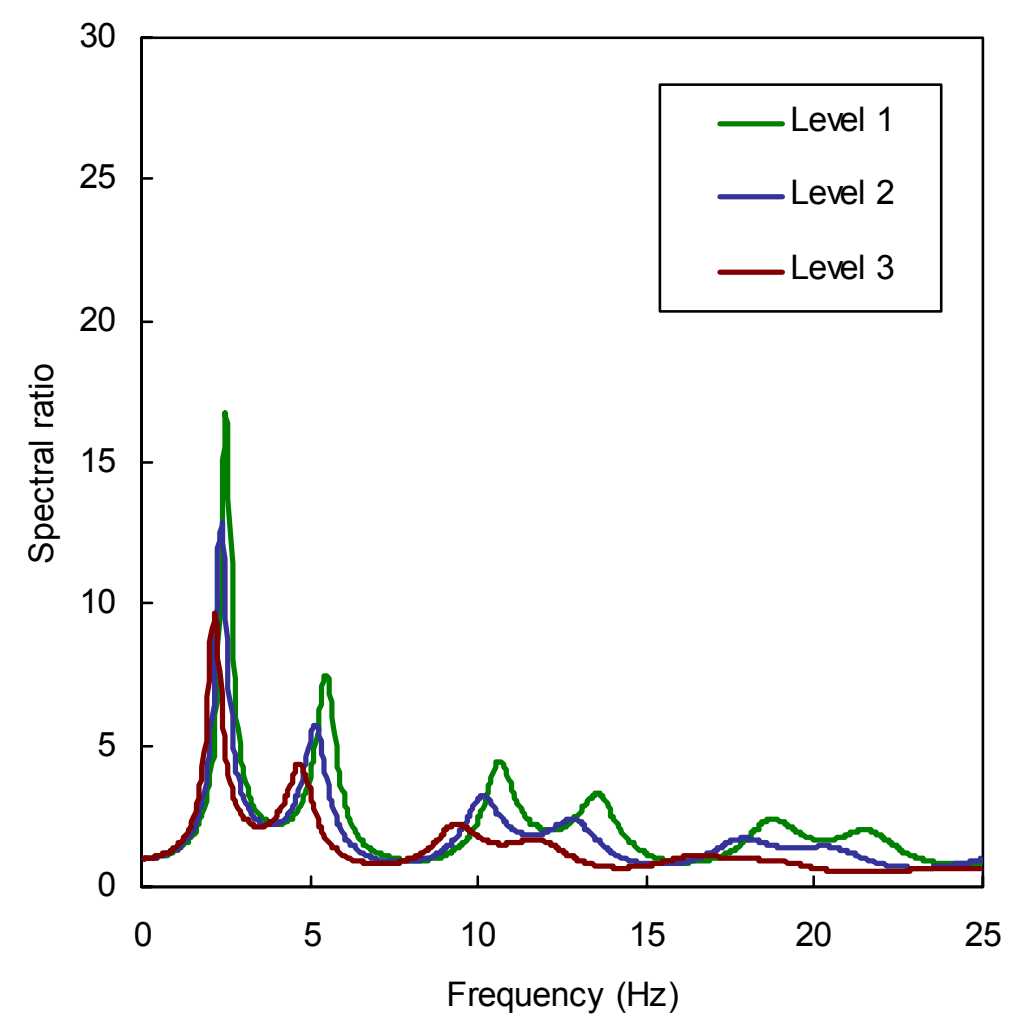

(a)

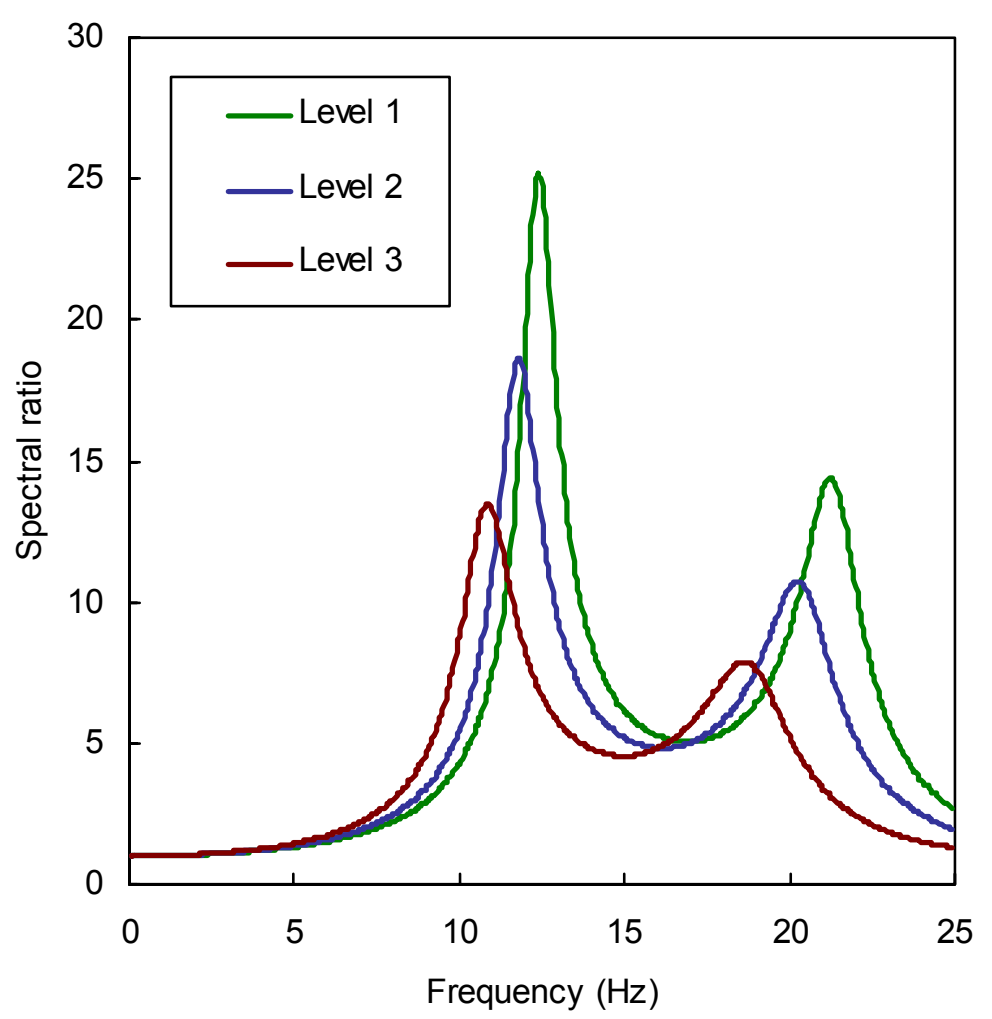

(b)

Figure 4. Transfer functions (surface-to-base) under various levels of motion intensity:

(a) horizontal component; (b) vertical component 


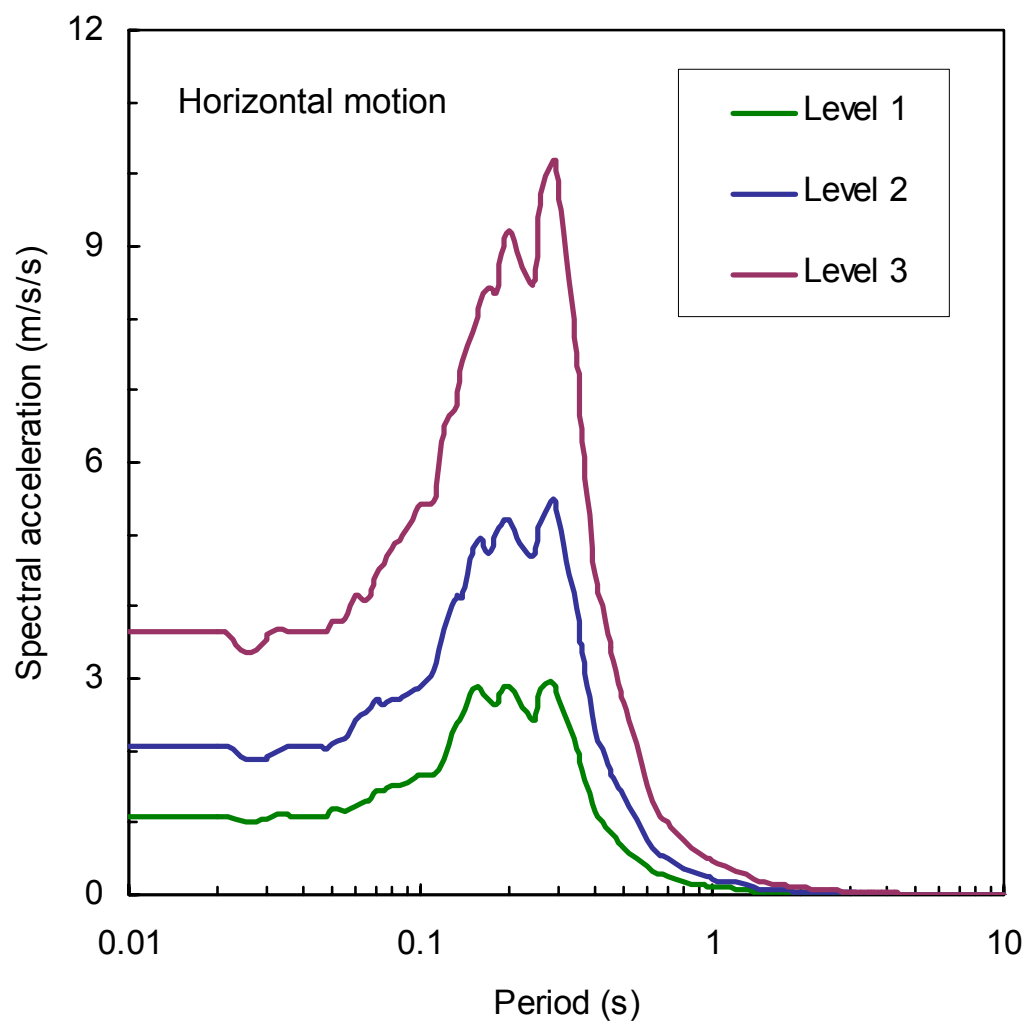

(a)

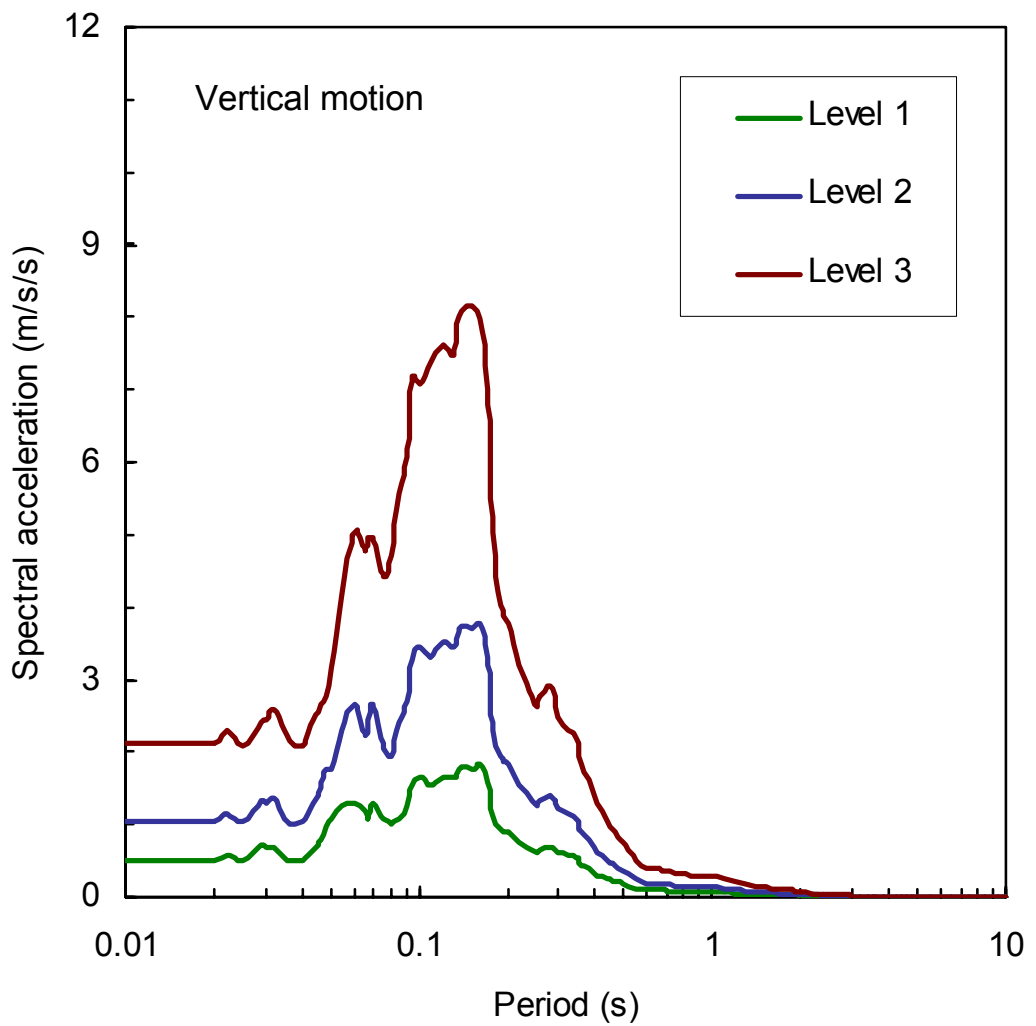

(b)

Figure 5. Response spectra of ground surface motions under various levels of motion intensity:

(a) horizontal component; (b) vertical component 


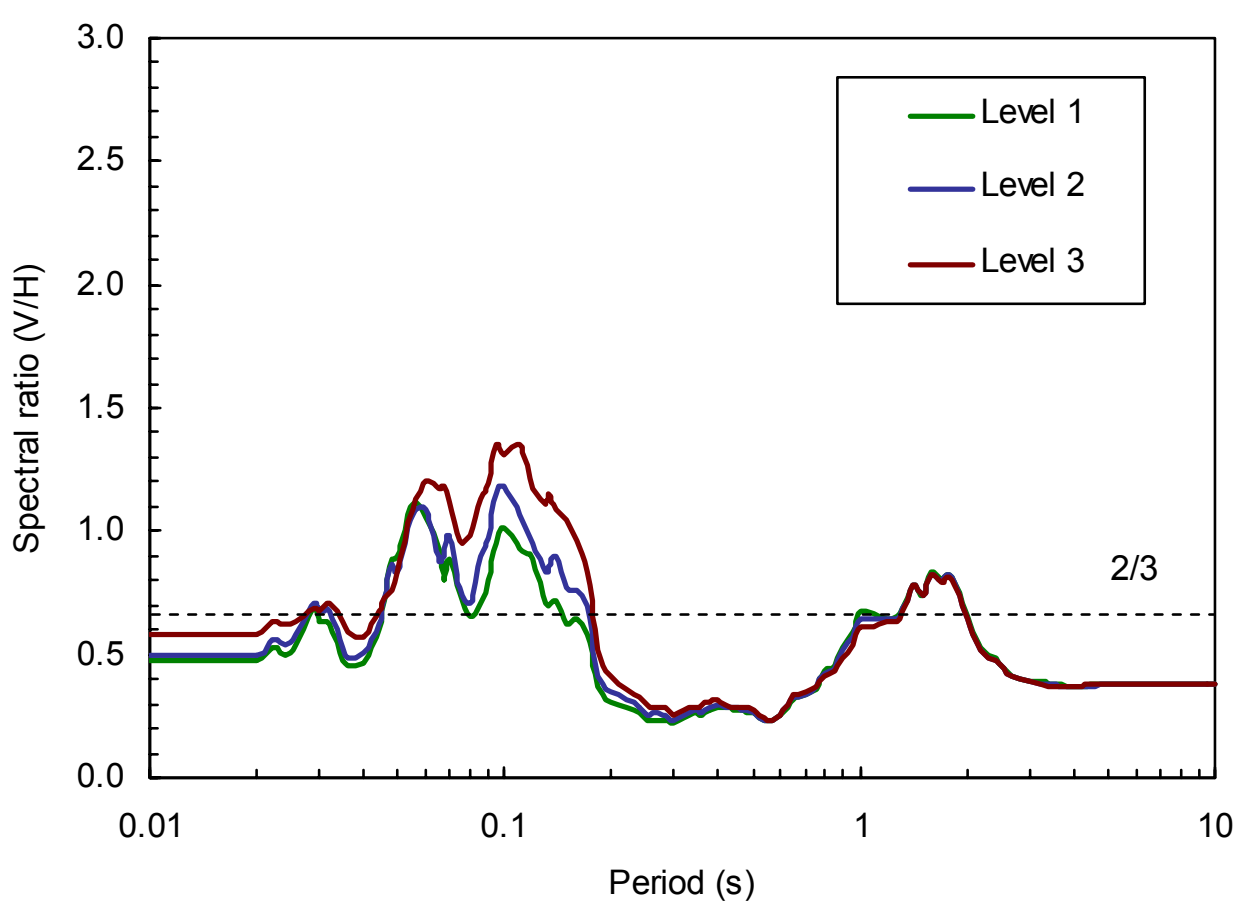

Figure 6. Influence of the intensity of input motion on the response spectral ratio between vertical and horizontal surface motions $(\mathrm{V} / \mathrm{H})$ 


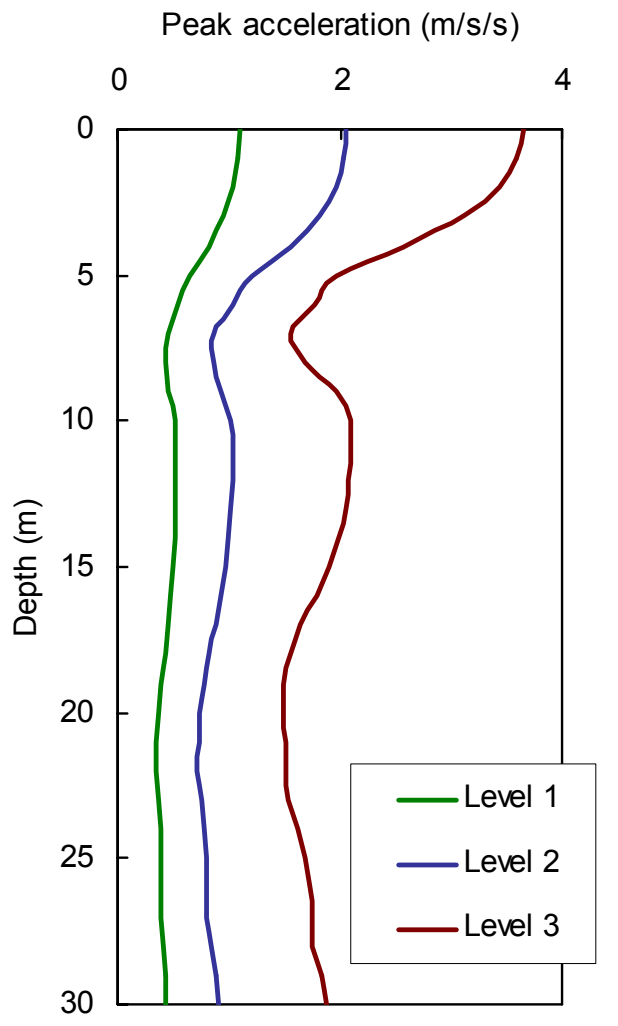

(a)

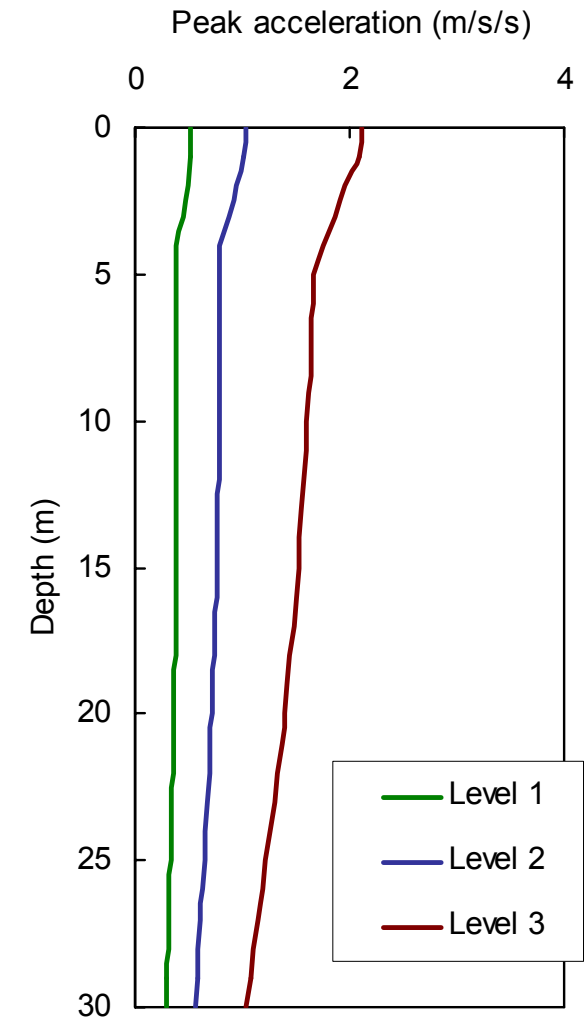

(b)

Figure 7. Influence of the intensity of input motion on distributions of peak accelerations with depth: (a) horizontal component; (b) vertical component 


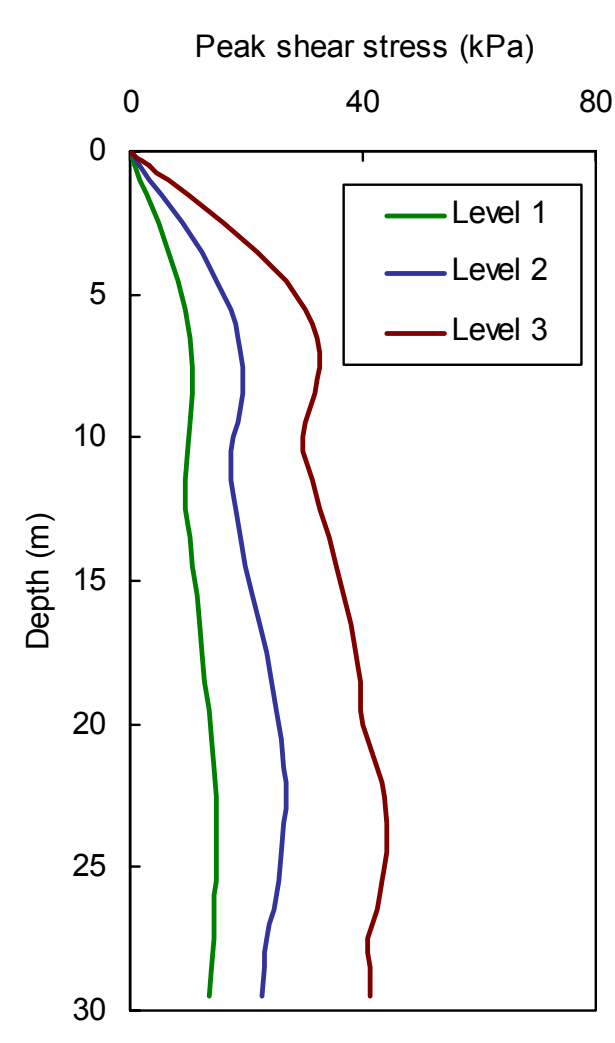

(a)

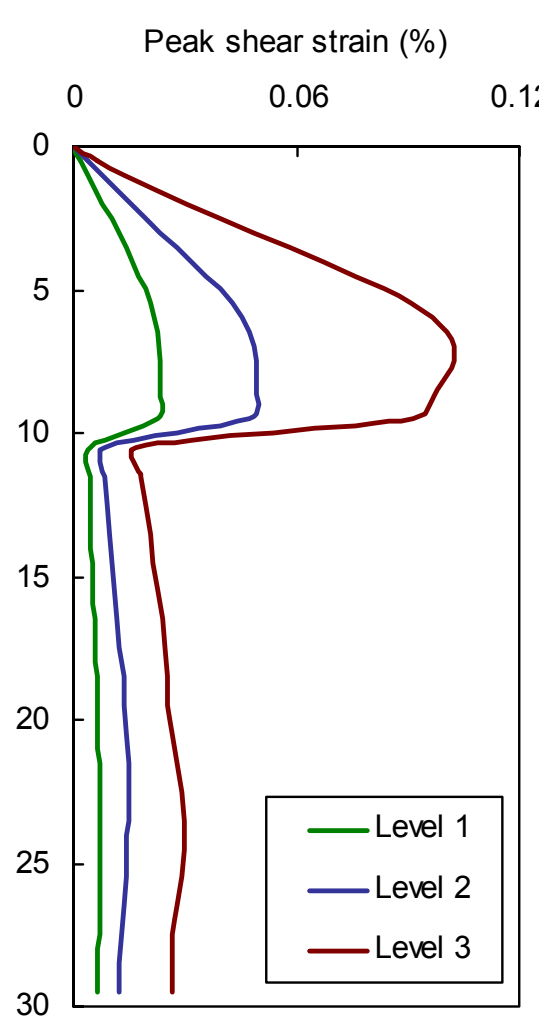

(b)

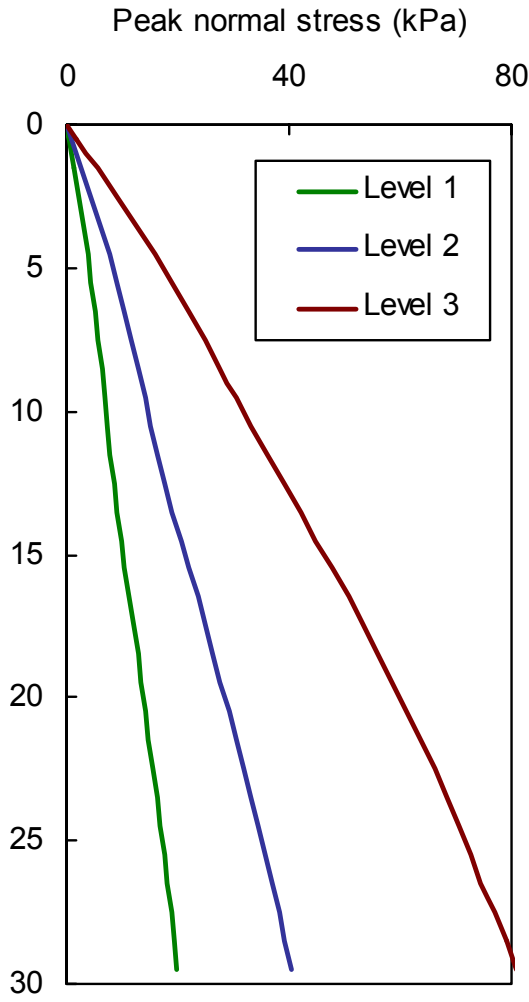

(c)
Peak normal strain (\%)

0.006 0.012

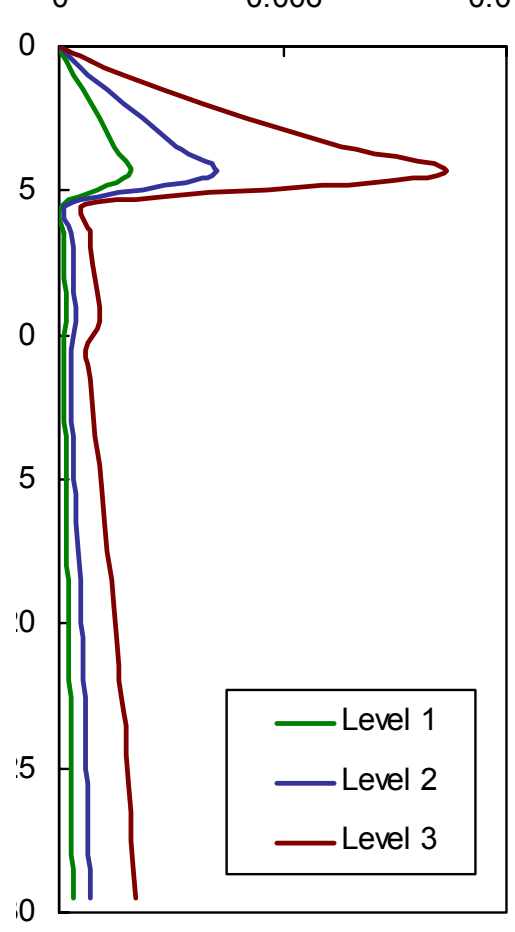

(d)

Figure 8. Influence of the intensity of input motion on distributions of stresses and strains with depth: (a) peak shear stress; (b) peak shear strain; (c) peak normal stress; (d) peak normal strain 


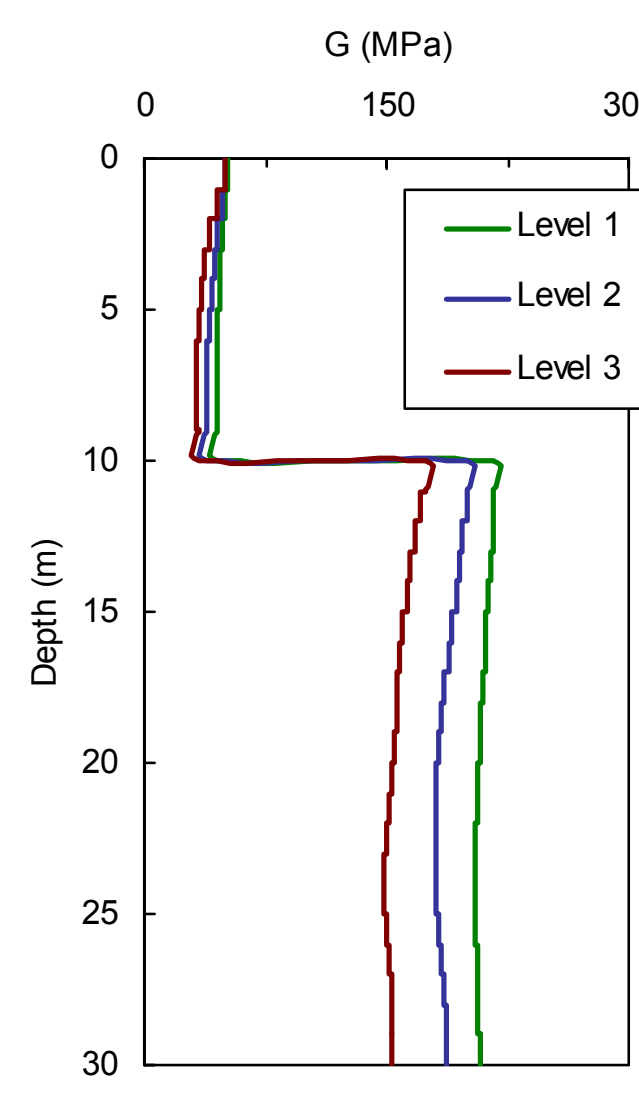

(a)
Ec (MPa)

4000

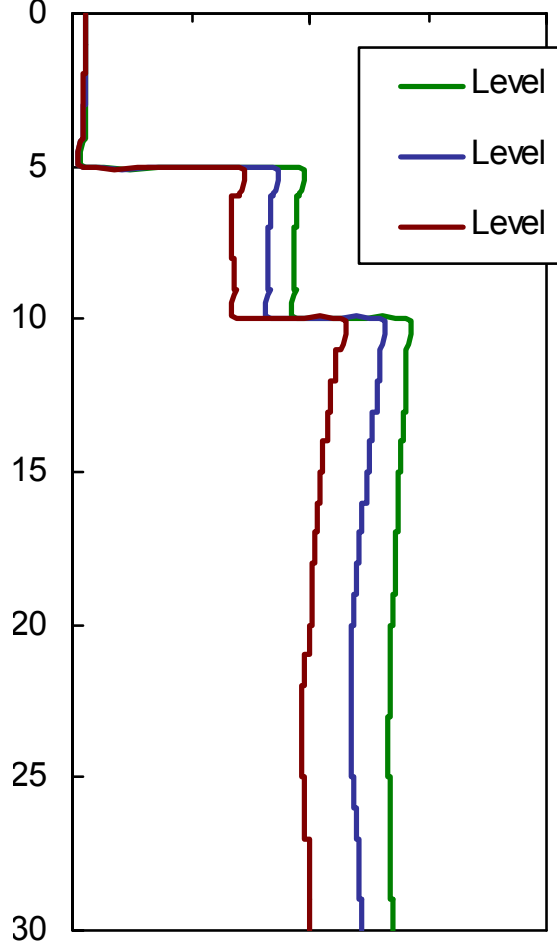

(b) $\zeta(\%)$

8

16

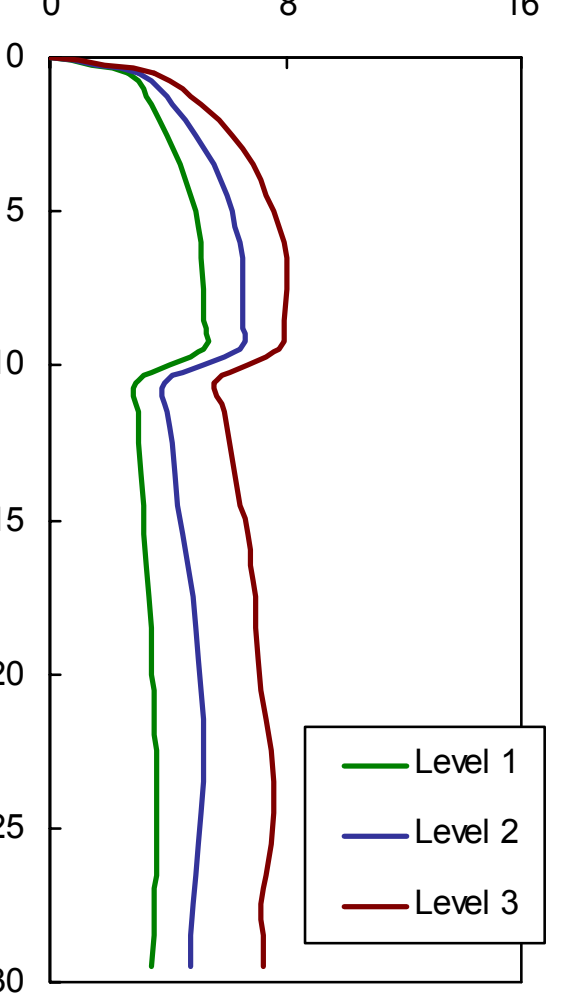

(c)

Figure 9. Influence of the intensity of input motion on distributions of degraded moduli and damping with depth: (a) shear modulus; (b) constrained modulus; (c) damping ratio 


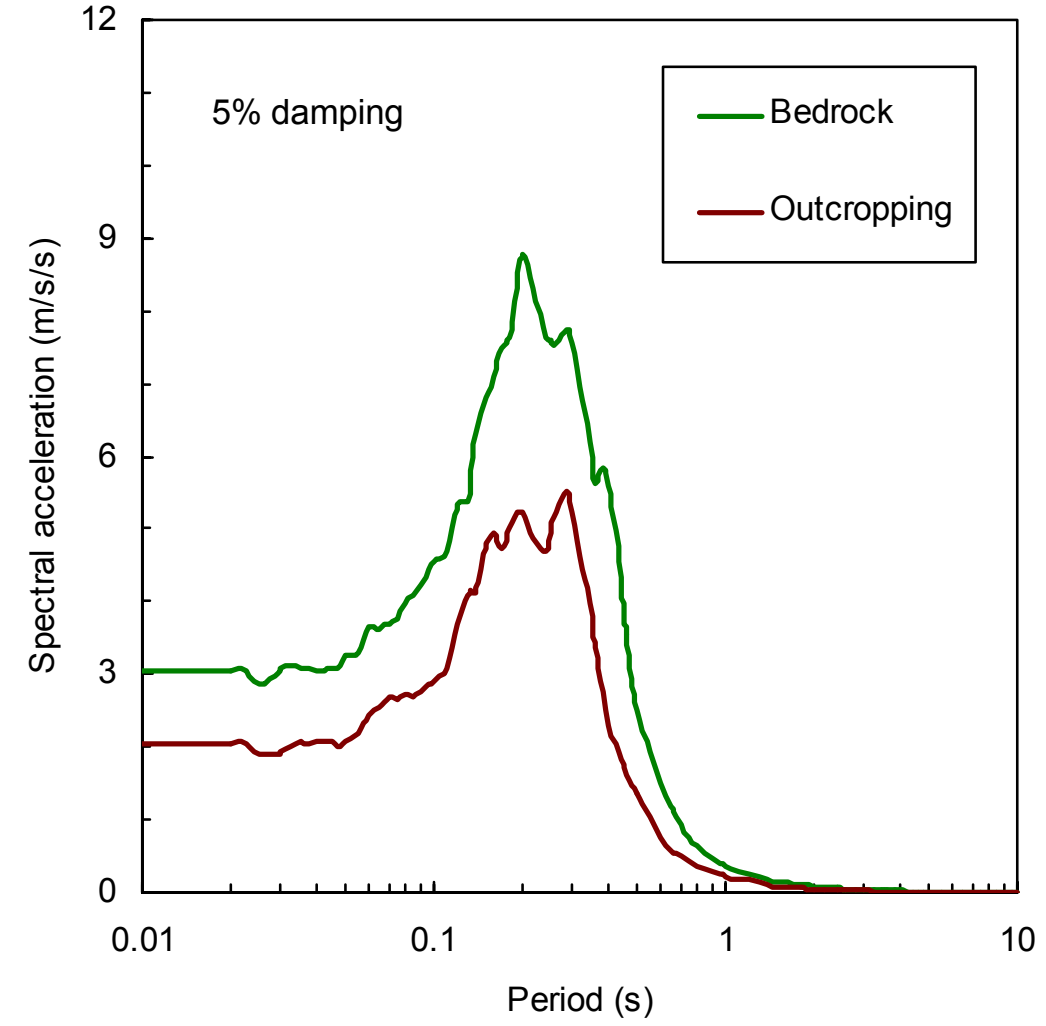

(a)

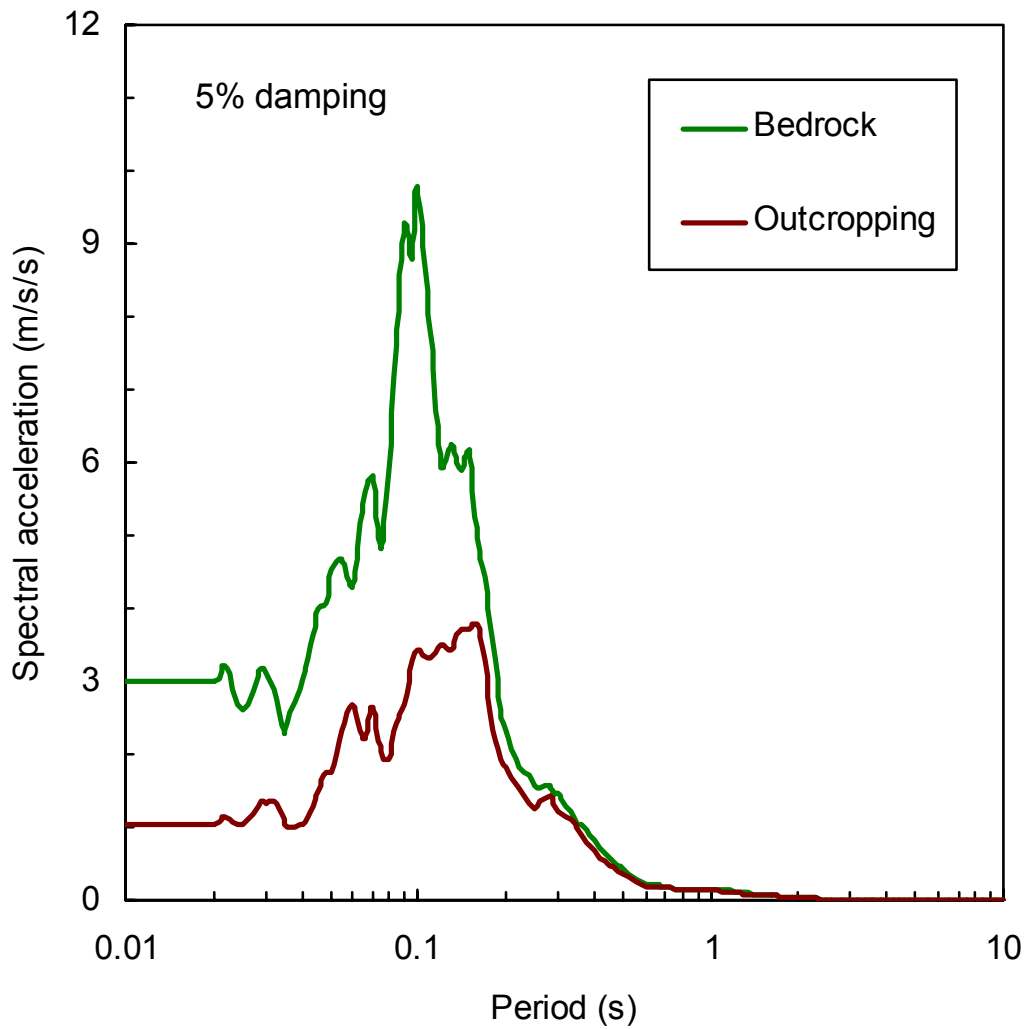

(b)

Figure 10. Influence of input motion position on the response spectra of ground surface motions: (a) horizontal component; (b) vertical component 


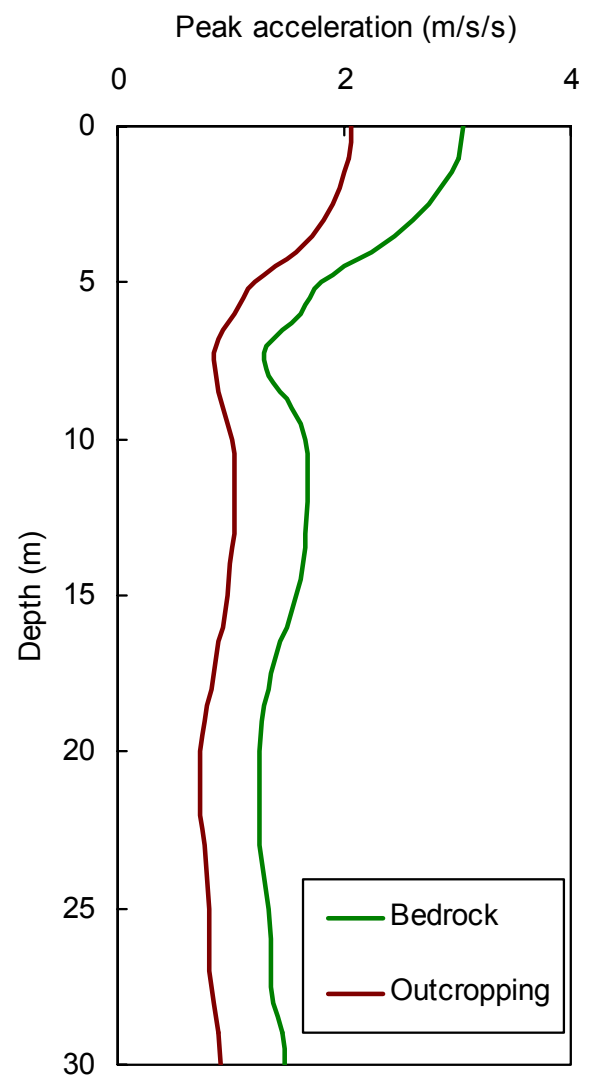

(a)

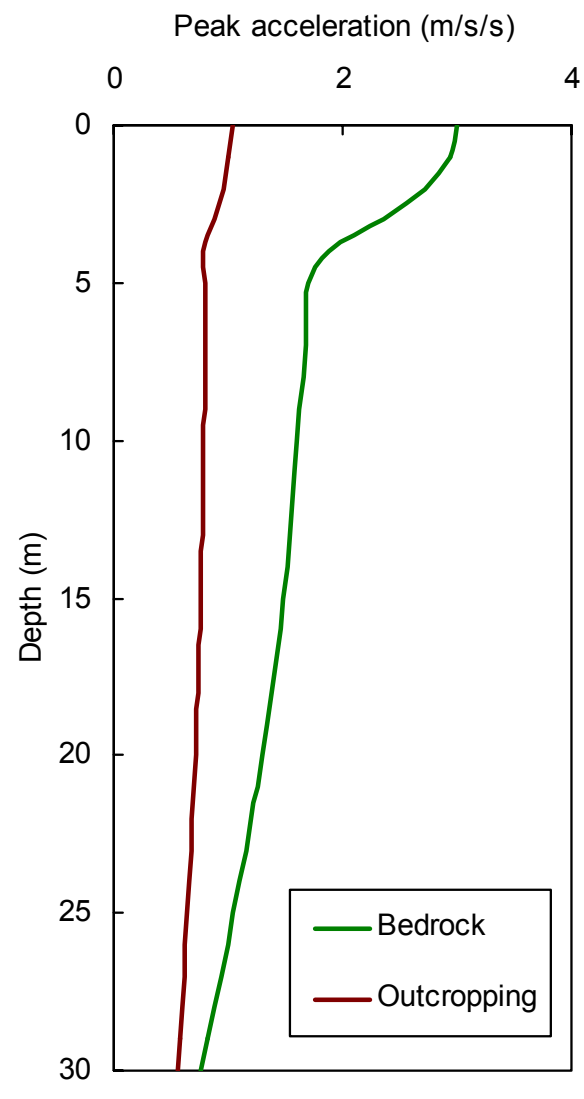

(b)

Figure 11. Influence of input motion position on distributions of peak accelerations with depth: (a) horizontal component; (b) vertical component 


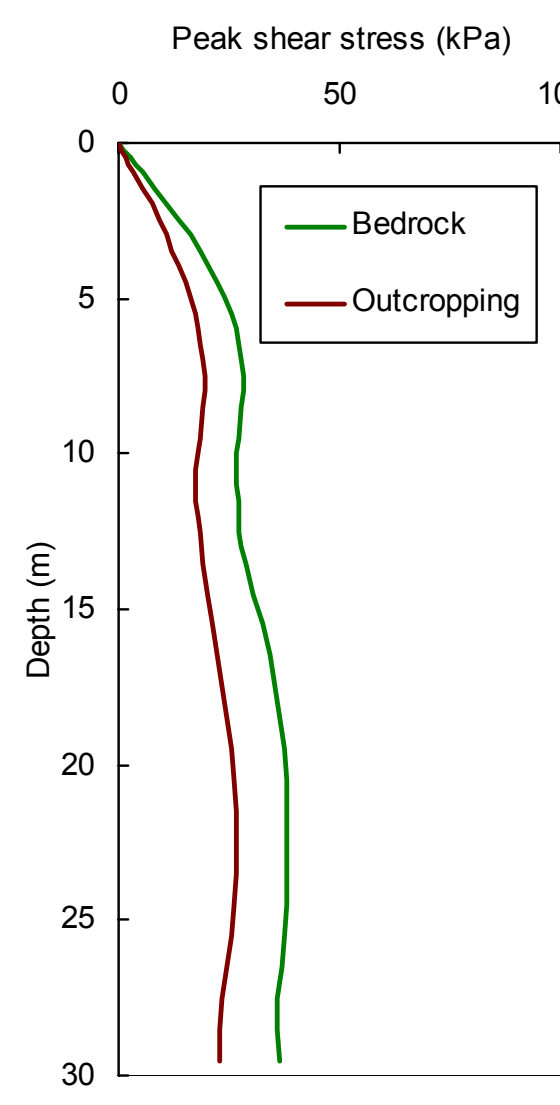

(a)

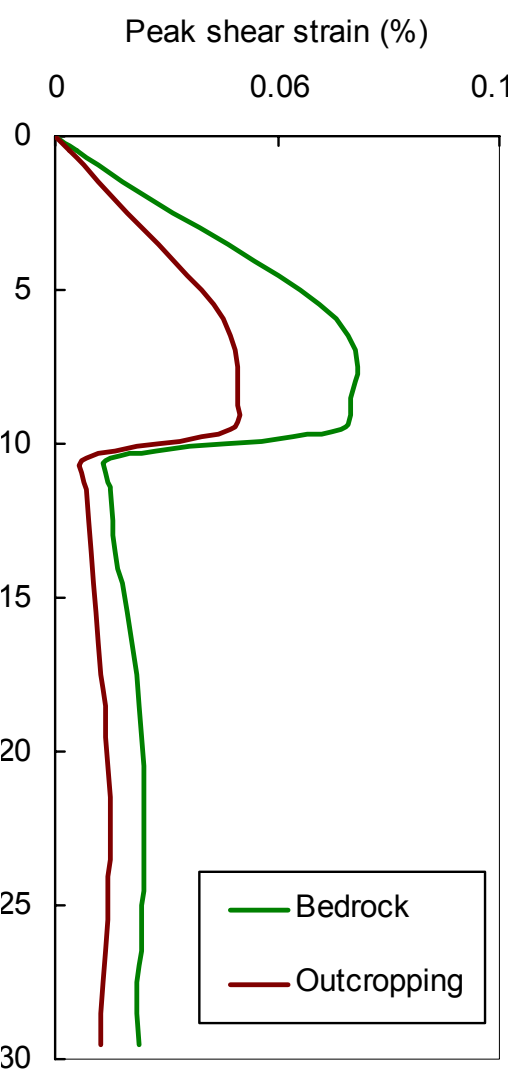

(b)

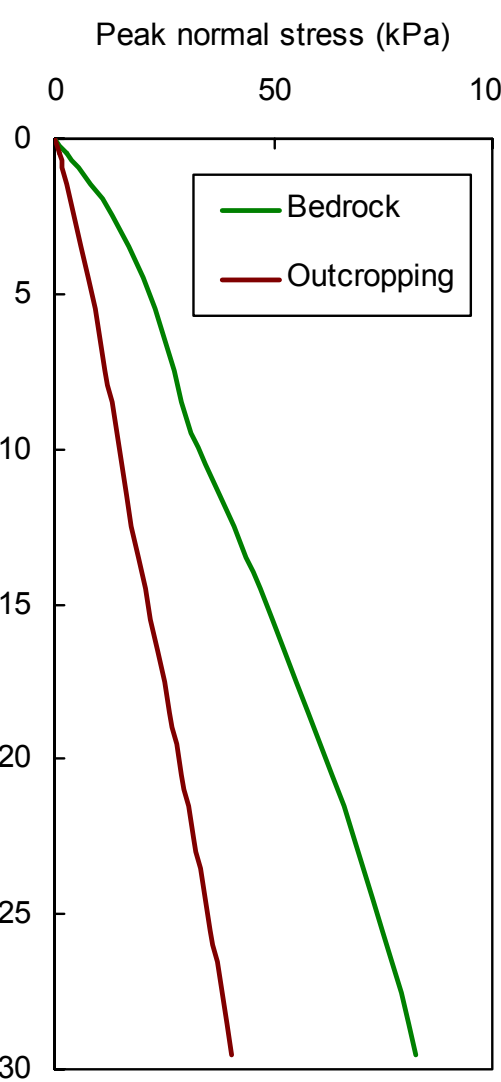

(c)
Peak normal strain $(\%)$

0.008

0.016

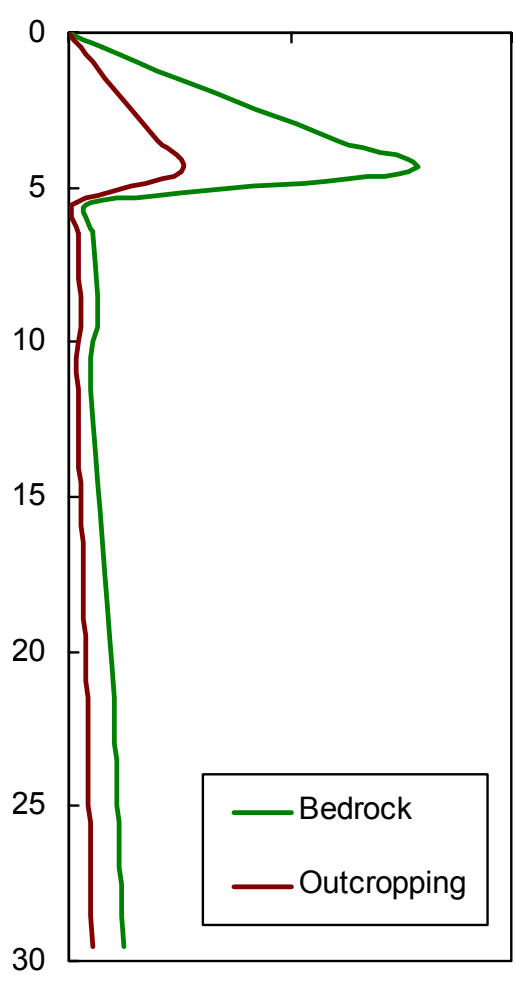

(d)

Figure 12. Influence of input motion position on distributions of stresses and strains with depth:

(a) peak shear stress; (b) peak shear strain; (c) peak normal stress; (d) peak normal strain 


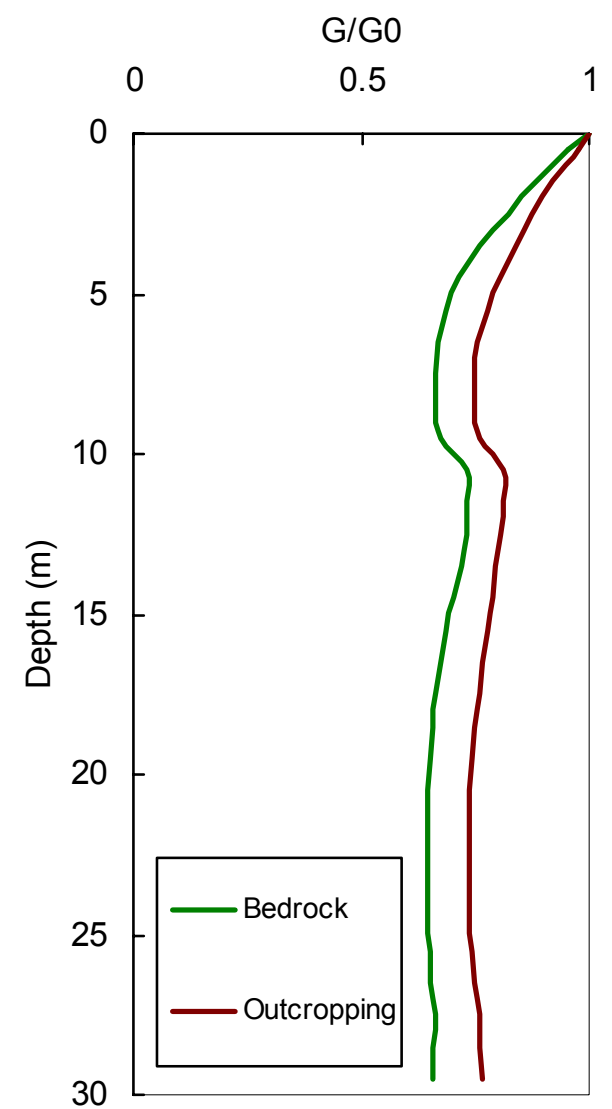

(a)

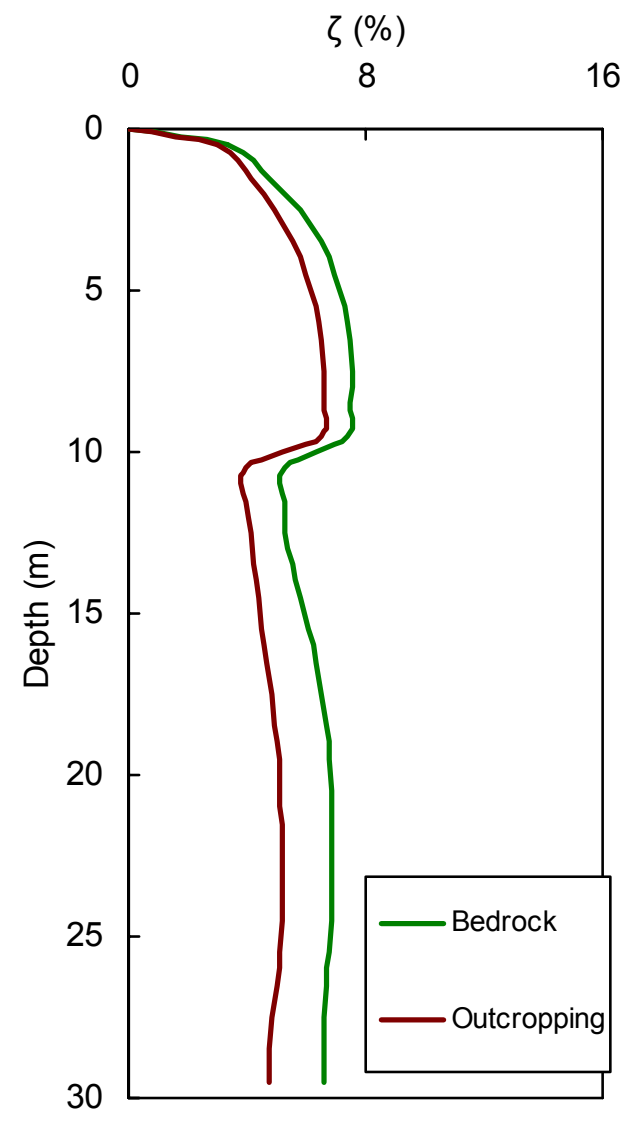

(b)

Figure 13. Influence of input motion position on distributions of (a) shear modulus reduction and (b) damping ratio 


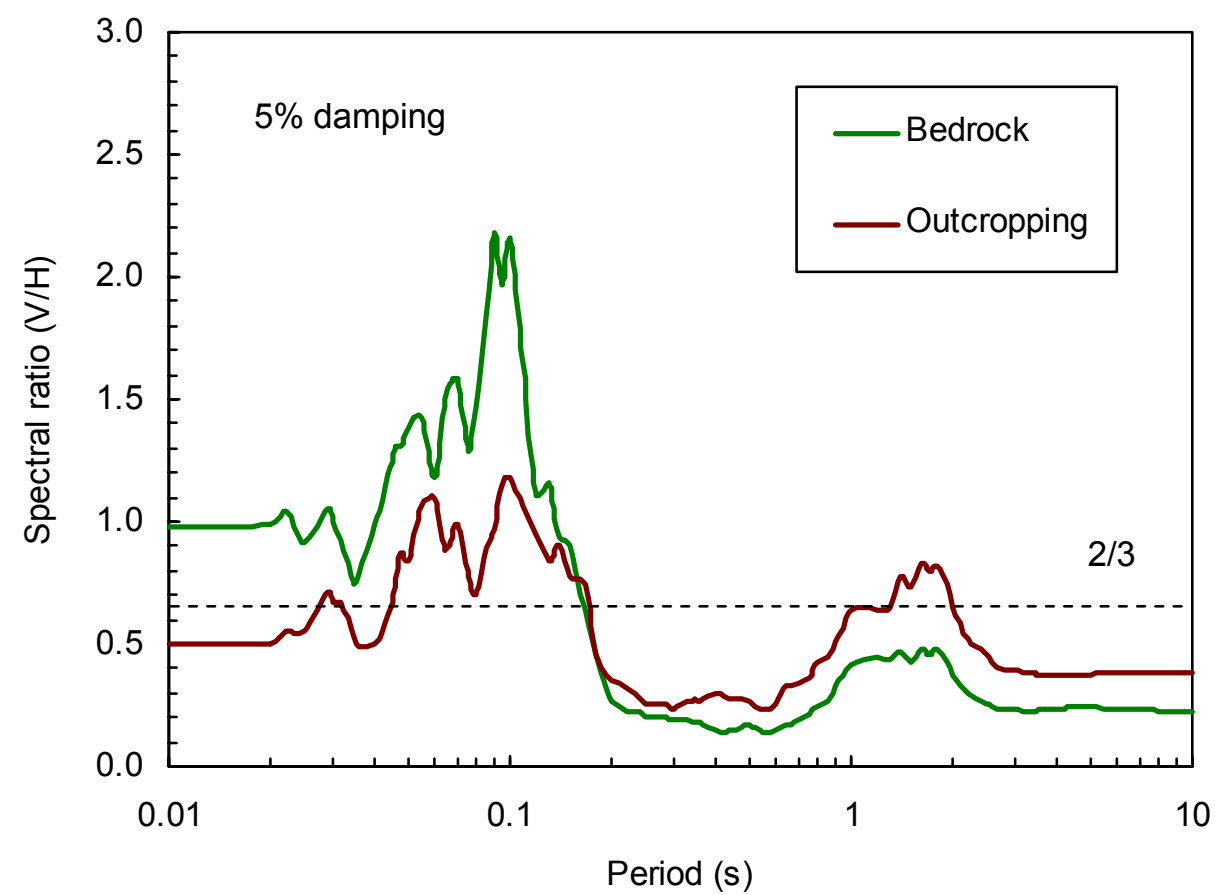

Figure 14. Influence of input motion position on the response spectral ratio between vertical and horizontal surface motions $(\mathrm{V} / \mathrm{H})$ 


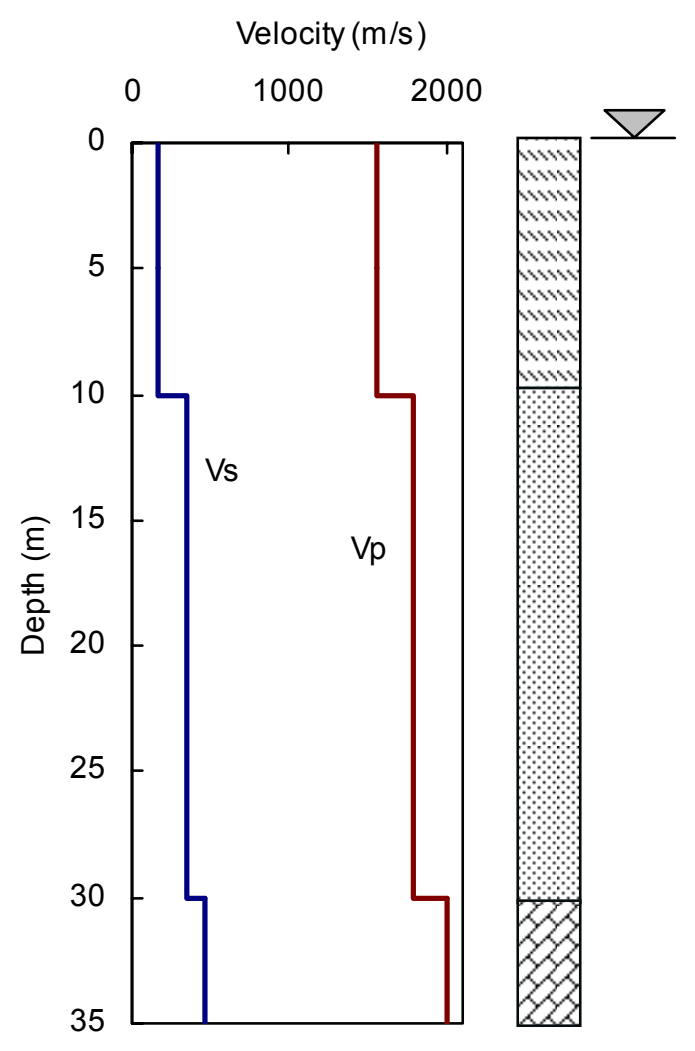

(a)

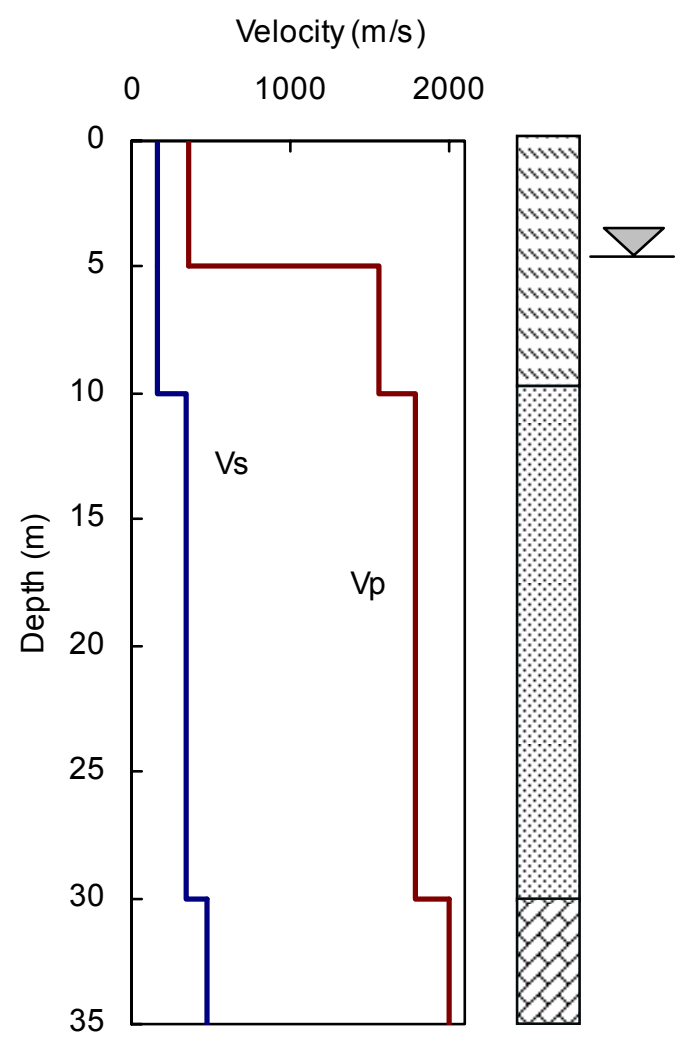

(b)

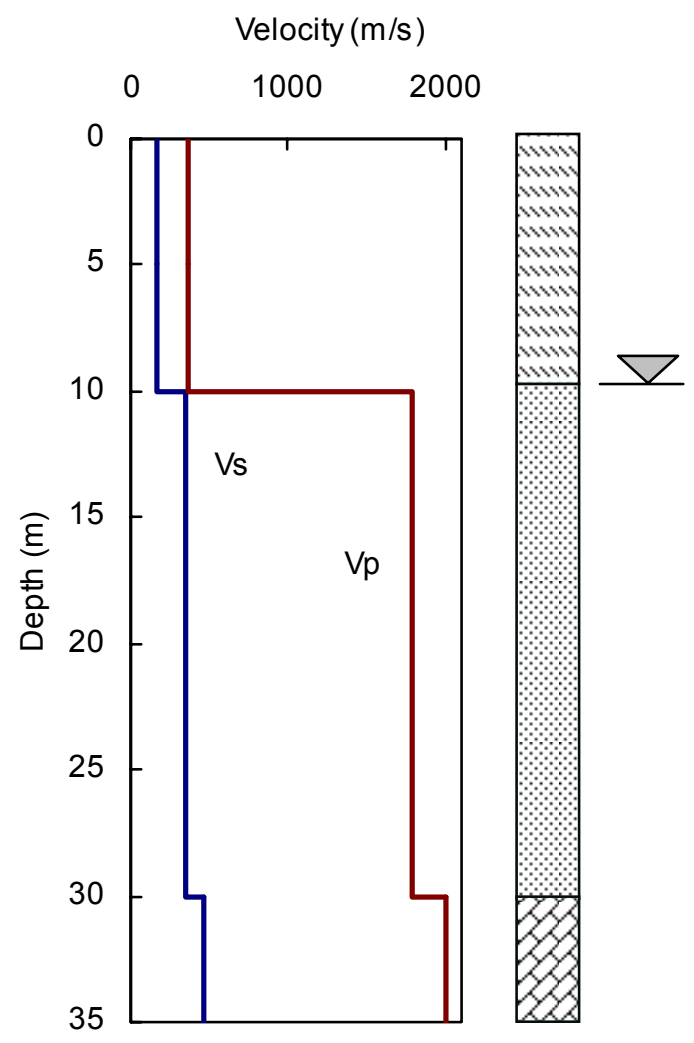

(c)

Figure 15. Three cases of water levels under investigation: (a) WL=0 m; (b) WL=5 m; (c) WL=10 m 

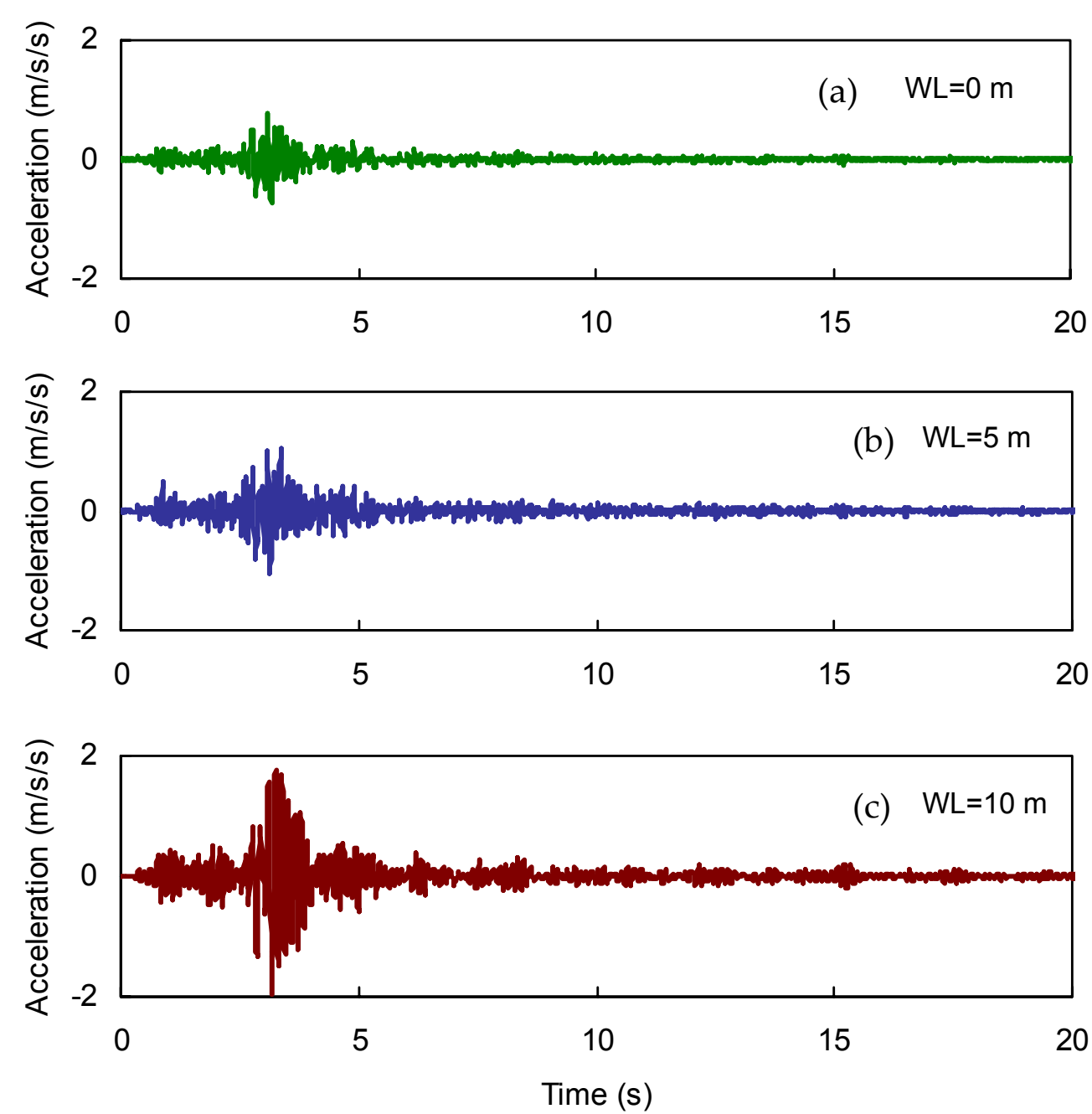

Figure 16. Vertical ground surface accelerations under various water levels: (a) $W L=0 \mathrm{~m}$; (b) $W L=5 \mathrm{~m}$; (c) $W L=10 \mathrm{~m}$ 


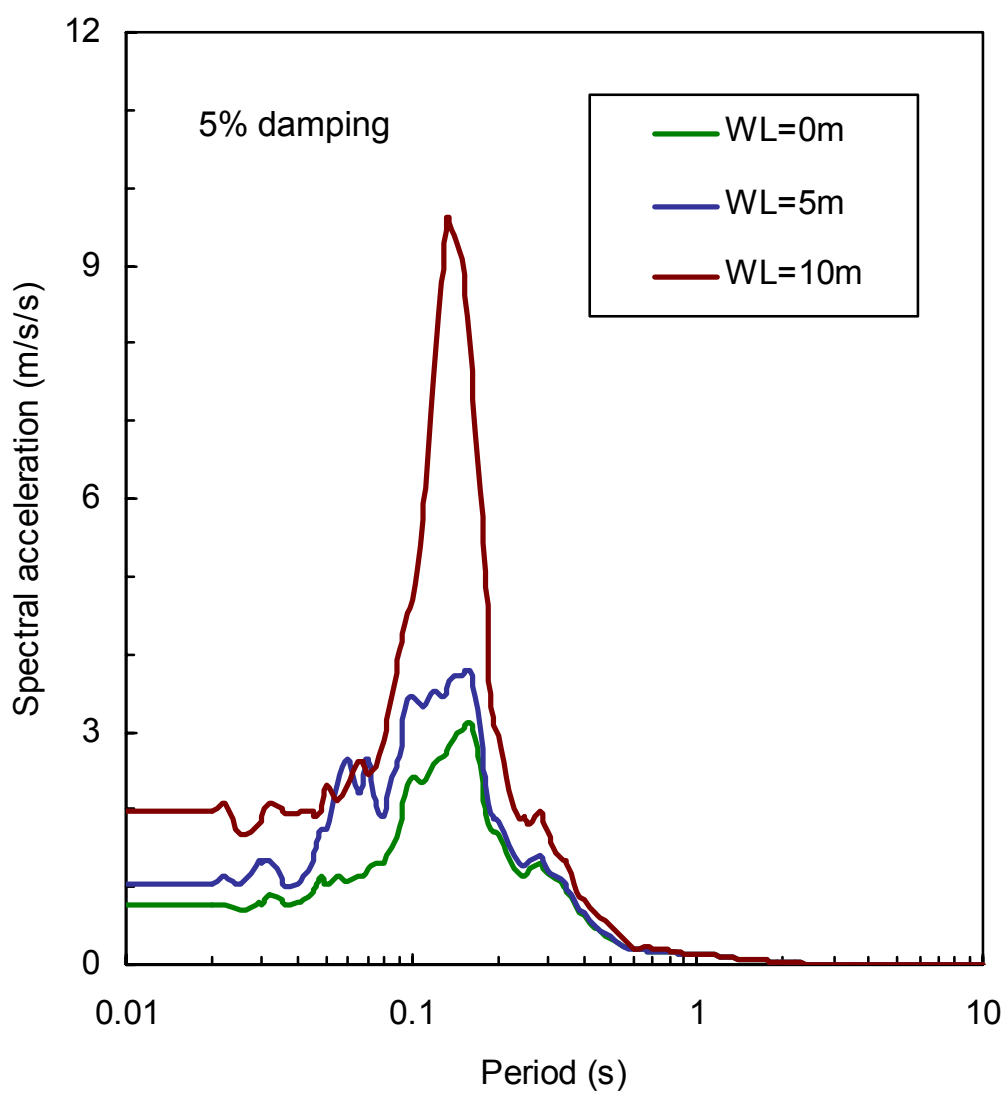

(a)

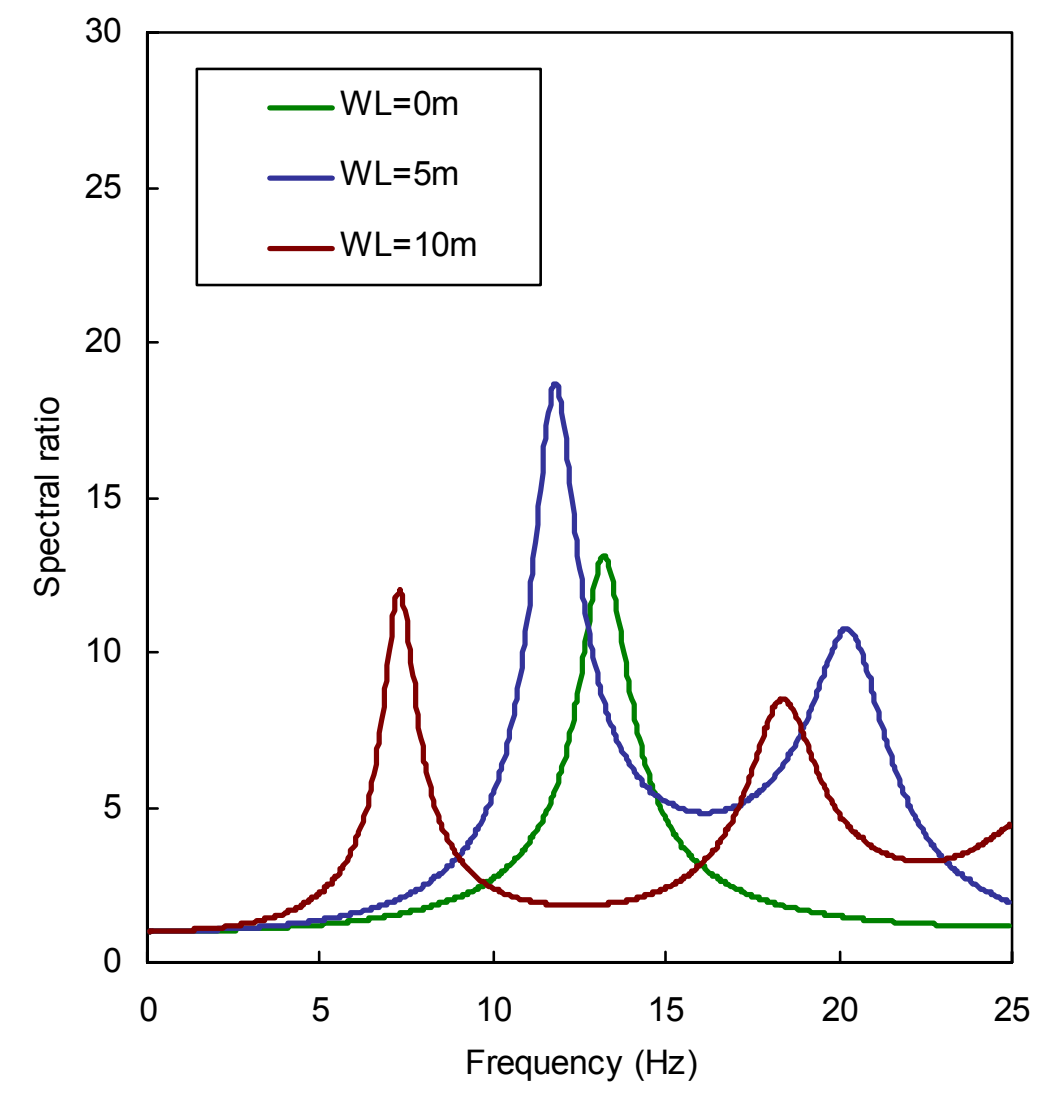

(b)

Figure 17. Influence of water level on vertical ground motion: (a) surface response spectra; (b) transfer function (surface-to-base) 


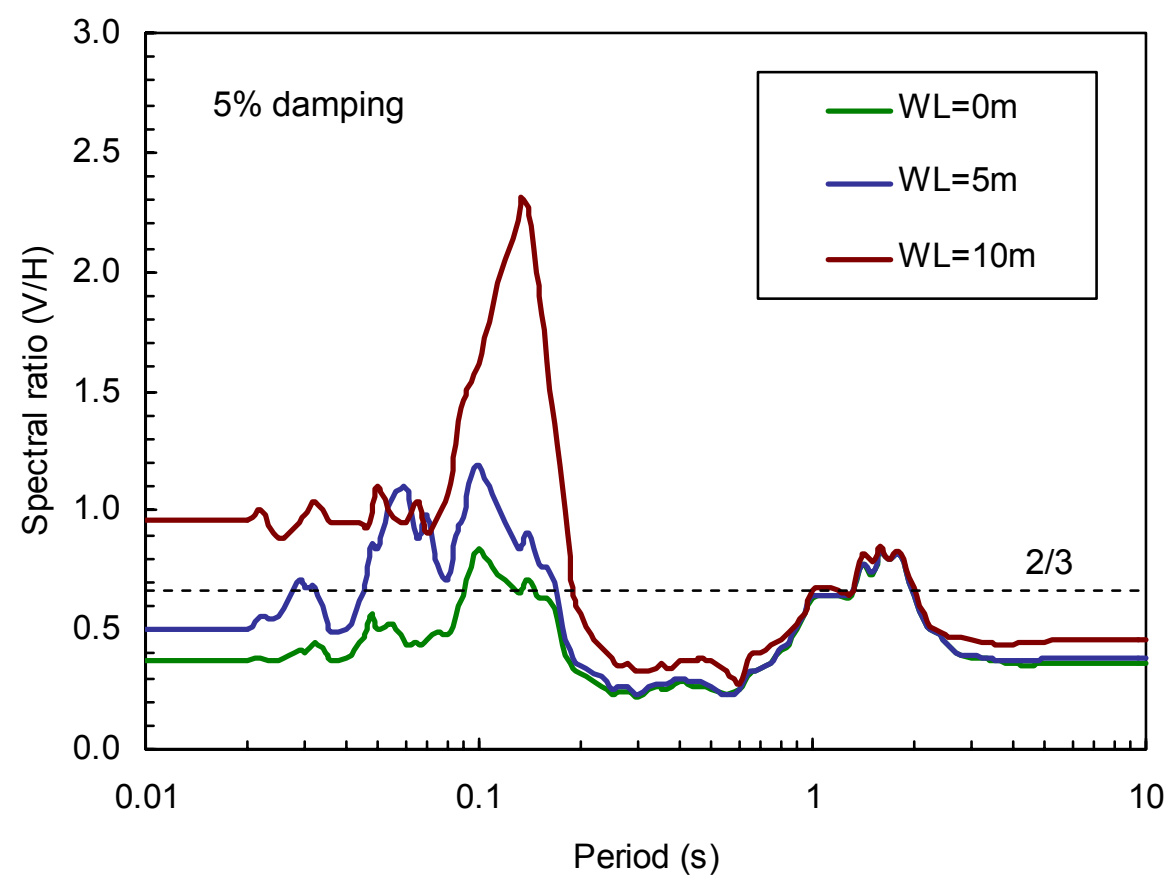

Figure 18. Influence of water level on the response spectral ratio between vertical and horizontal surface motions $(\mathrm{V} / \mathrm{H})$ 


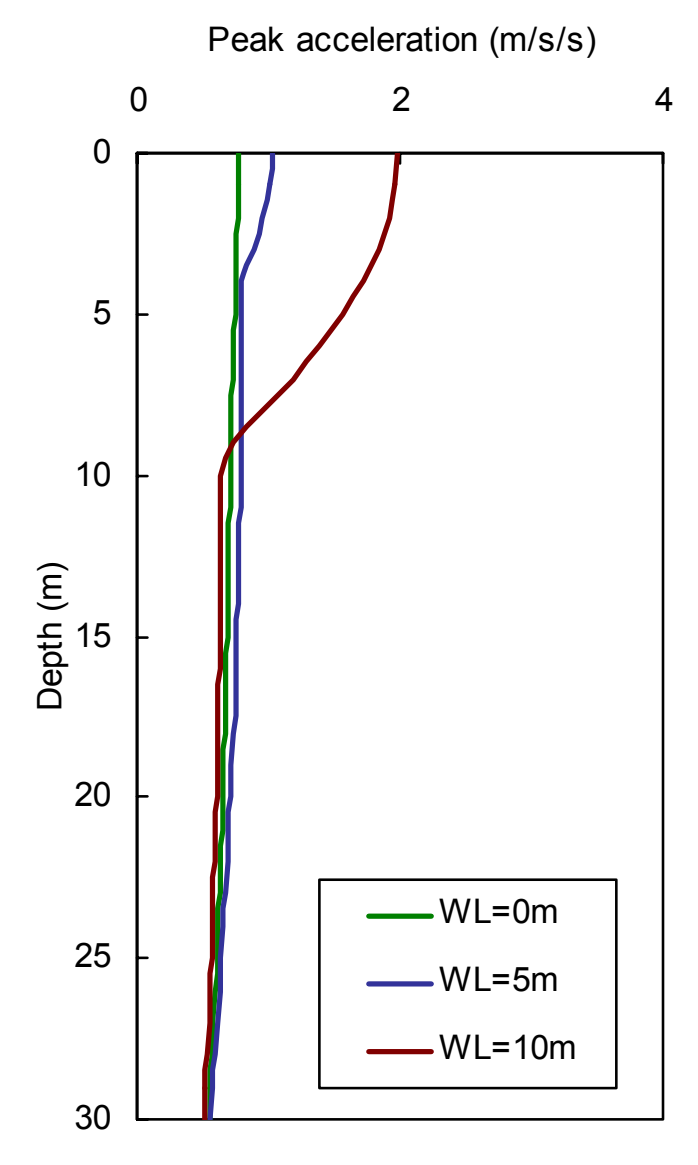

(a)

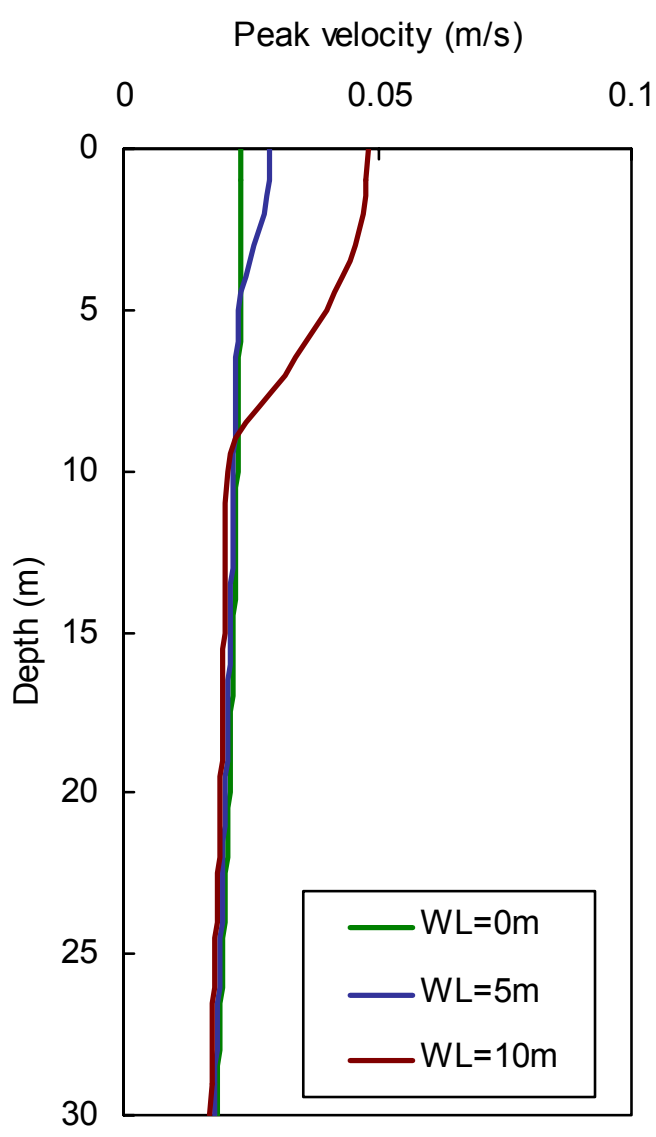

(b)

Figure 19. Influence of water level on distributions of (a) peak vertical acceleration and (b) peak vertical velocity 


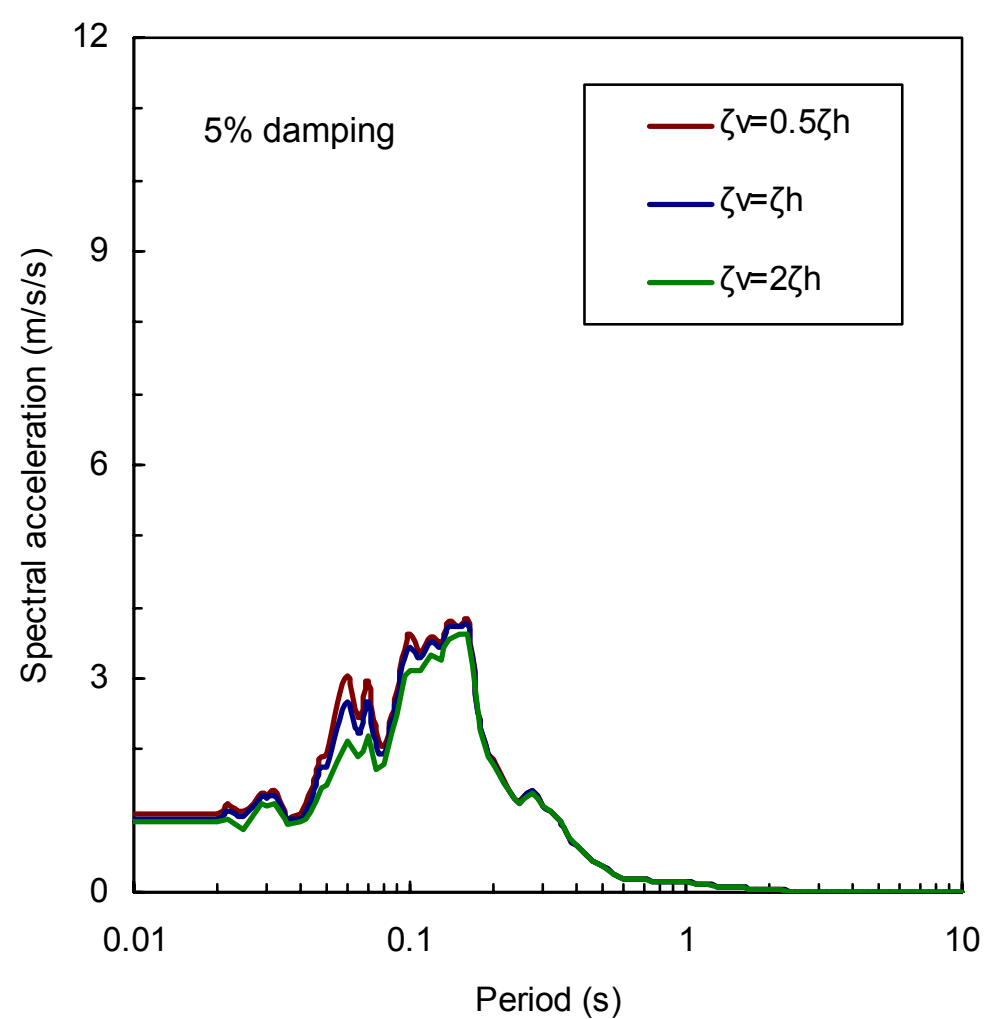

(a)

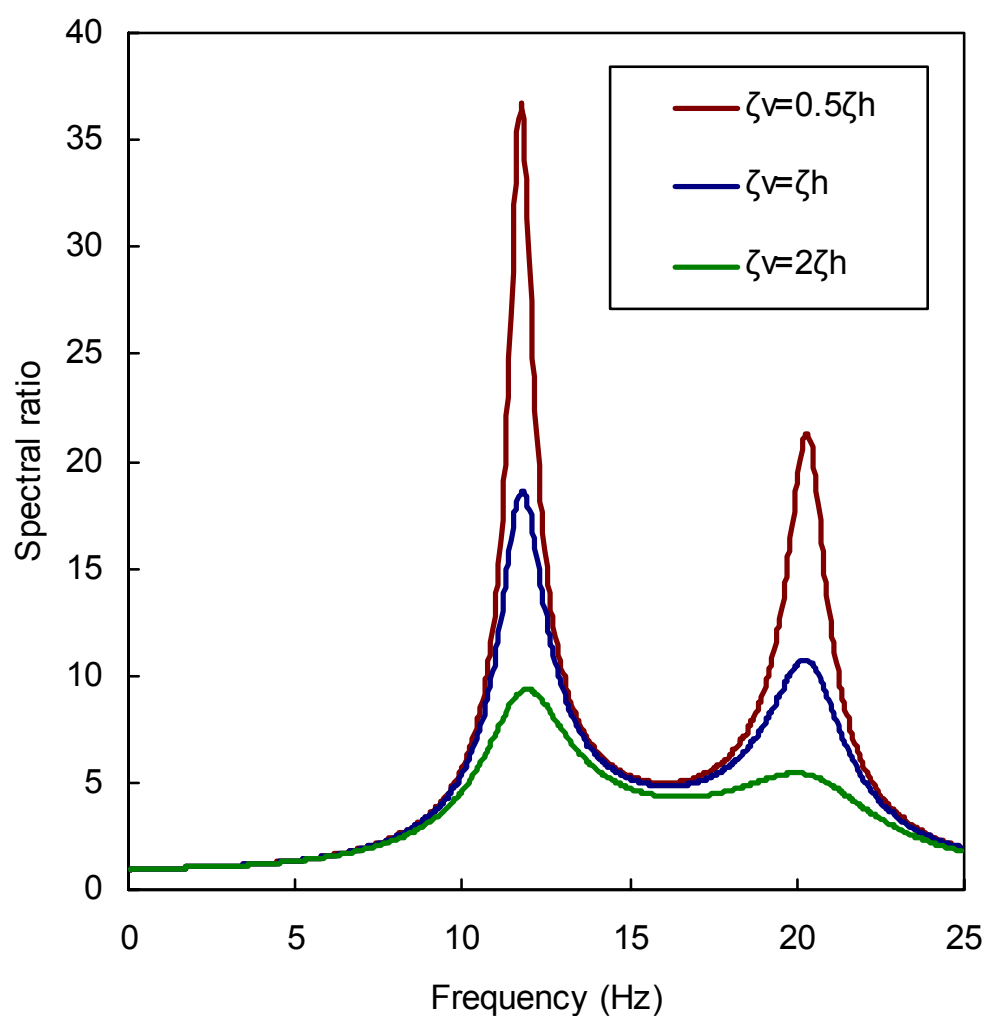

(b)

Figure 20. Influence of damping ratio on vertical ground motion: (a) surface response spectra; (b) transfer function (surface-to-base) 


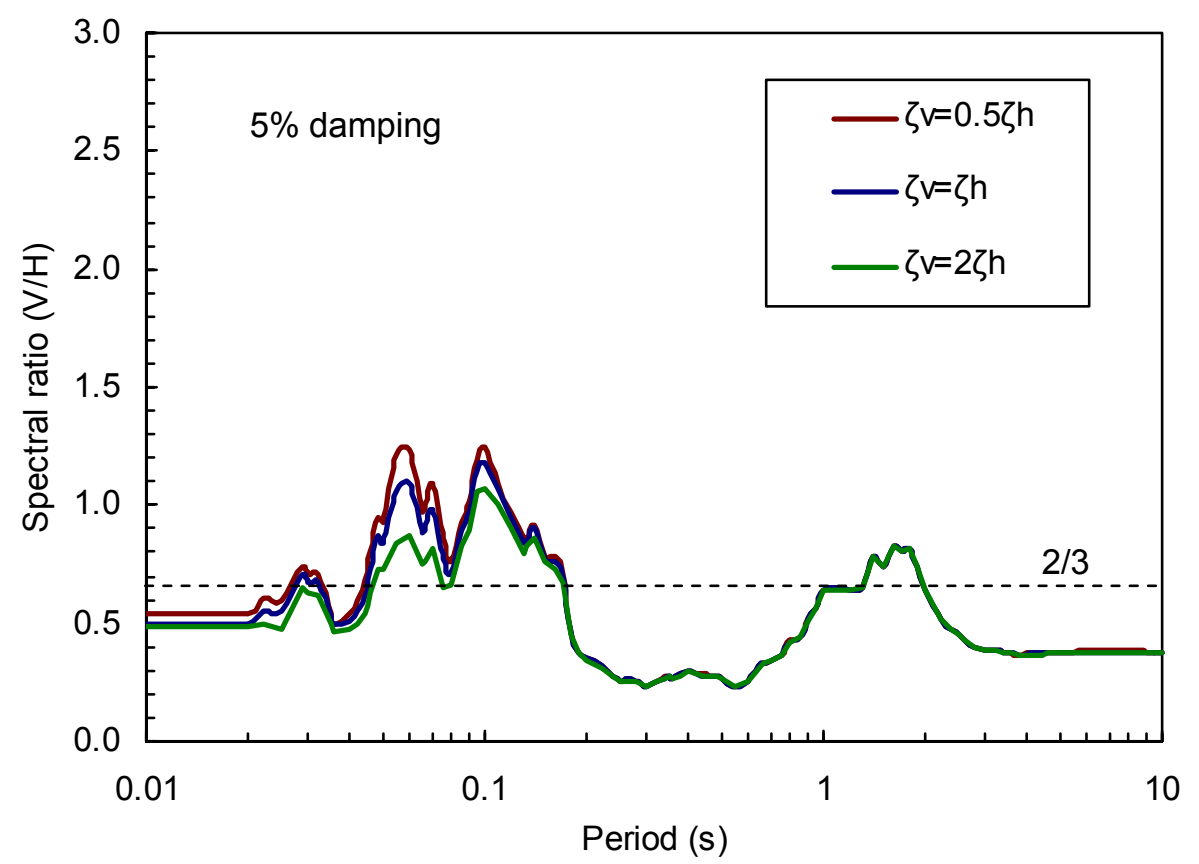

Figure 21. Influence of damping ratio on the response spectral ratio between vertical and horizontal surface motions $(\mathrm{V} / \mathrm{H})$ 